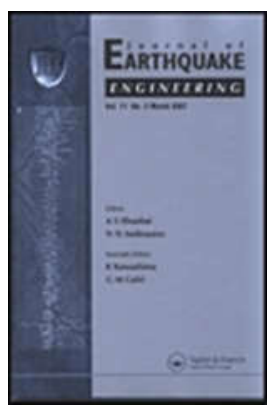

\title{
Plastic Hinge Length for Lightly Reinforced Rectangular Concrete Walls
}

\begin{tabular}{|r|l|}
\hline Journal: & Journal of Earthquake Engineering \\
\hline Manuscript ID & UEQE-2016-2442.R2 \\
\hline Date Submitted by the Author: & n/a \\
\hline Complete List of Authors: & $\begin{array}{l}\text { Hoult, Ryan; The University of Melbourne, Department of Infrastructure } \\
\text { Goldsworthy, Helen; University of Melbourne, Civil and Environmental } \\
\text { Engineering } \\
\text { Lumantarna, Elisa; The University of Melbourne, Civil and Environmental } \\
\text { Engineering }\end{array}$ \\
\hline Keywords: & wall, cracking, non-ductile, reinforced, concrete, plasticity \\
\hline & \\
\hline
\end{tabular}

\section{SCHOLARONE}

Manuscripts 


\title{
Plastic Hinge Length for Lightly Reinforced
}

\section{Rectangular Concrete Walls}

\author{
Ryan Hoult ${ }^{1,4}$, Helen Goldsworthy ${ }^{2,4}$, Elisa Lumantarna $a^{3,4}$
}

1. Corresponding Author. PhD Candidate, Department of Infrastructure Engineering, University of Melbourne, Parkville, 3010, Australia. Email: rhoult@,student.unimelb.edu.au. Ph:+61401955374

2. Associate Professor, Department of Infrastructure Engineering, University of Melbourne, Parkville, 3010, Australia. Email: helenmg@unimelb.edu.au

3. Lecturer, Department of Infrastructure Engineering, University of Melbourne, Parkville, 3010, Australia. Email: elu@unimelb.edu.au

4. Bushfire and Natural Hazards Cooperative Research Centre, Melbourne, Australia

\section{Abstract}

This research investigates the plastic hinge length in lightly reinforced rectangular walls typically found in regions of low-to-moderate seismicity. Poor performance has been exhibited by lightly reinforced concrete walls in past earthquake events. A series of finite element analyses have been carried out which demonstrate that if the longitudinal reinforcement ratio in the wall is below a certain threshold value, there will not be sufficient reinforcement to cause secondary cracking, and instead fracture of the longitudinal reinforcement at a single crack could occur. A plastic hinge length equation has been derived based on the results from the numerical simulations.

\section{Introduction}

Reinforced concrete (RC) walls and cores are widely used throughout the building stock in areas of low-to-moderate seismic regions such as Australia. Such elements are used as the primary structure in resisting lateral loads, including those generated from seismic ground motions. Due to the inadequacy of the rules governing detailing in the material codes and the low values of earthquake actions used for design in regions of low-to-moderate seismicity, it is anticipated that some walls and cores in these buildings have very limited ductility (Hoult et al., 2015; Wibowo et al., 2013). Some lightly RC walls were observed to perform poorly in the February $22^{\text {nd }}$ Christchurch earthquake, with several cases of a single crack forming at the base in contrast to the expected distributed cracks 
30 (CERC, 2012). Moreover, it was common to find in these walls that some of the longitudinal

31 reinforcing bars that crossed the crack had fractured prematurely due to the large concentration of

32 inelastic deformations developing over such a small length (CERC, 2012). The Canterbury

33 Earthquakes Royal Commission (CERC, 2012) noted that in the collapse of the Pyne Gould

34 Corporation Building 'it was unlikely that sufficient tension could have been transmitted to initiate a secondary crack in the concrete' due to the low amount of vertical reinforcement, and subsequent 'yielding of reinforcement being confined to a short length resulting in a single wide crack in the potential plastic region at level 1 [the base of the wall]'. This observation is of major concern for areas of low-to-moderate seismicity, such as Australia, where the great majority of the buildings incorporate RC walls with low longitudinal reinforcement ratios (Wibowo et al., 2013). The current concrete material standard AS 3600 (Standards Australia, 2009) in Australia enforces a minimum longitudinal reinforcement ratio of $0.15 \%$ for $\mathrm{RC}$ walls, which has been derived for the control of shrinkage and thermal effects as stated in the AS 3600 Commentary (Standards Australia, 2014) and due consideration is not given to ductility. Moreover, this minimum requirement is comparable to the $0.16 \%$ that was used in the Gallery Apartments building, one of the buildings that failed with a single crack failure in the Christchurch earthquake event (Henry, 2013; Henry et al., 2014; Sritharan et al., 2014).

A single crack failure has also been observed in experimental testing on $\mathrm{RC}$ walls. One of the RC walls experimentally tested by Cardenas and Magura (1972) and further analysed by Wood (1989) was observed to form a single, primary crack at the base of the wall before fracturing of the reinforcing bars occurred. This observation led Wood (1989) to conclude that walls that have a longitudinal reinforcement ratio less than $1 \%$ are susceptible to premature fracture. Moreover, there is a growing emphasis in the recent literature of the need for a sufficient amount of longitudinal reinforcement in $\mathrm{RC}$ walls in order to achieve a ductile performance. A concentration of reinforcement at the boundary is recommended by Moehle (2015) for 'promoting better distribution of flexural cracks' and concern is expressed about the possibility of the tensile strength of the concrete being higher than the tensile strength of the longitudinal reinforcement at the (primary) cracked 
57 section. The authors from SRIA (2015) comment on the potential for a lightly reinforced wall to

58 develop localised strains when subjected to earthquake ground motions.

59 Due to the recent observations from the Christchurch earthquake for lightly reinforced walls, there is a

60 need to investigate the amount of longitudinal reinforcement required to initiate secondary cracking

61 and allow a distribution of plasticity. If single-crack failures are to be expected in lightly reinforced walls, it is likely that the plastic hinge length equations, that have been developed with reference to walls in which a distribution of cracks occur, will overestimate the displacement capacity of these walls and be unsuitable. These results are essential knowledge for vulnerability studies of reinforced concrete buildings that are being carried out by the authors within the earthquake mitigation component of the Australian CRC (Cooperative Research Centre) for Bushfires and Natural Hazards.

\section{Secondary Cracking - simple approach}

Past research has indicated the dangers of lightly reinforced concrete walls inherently having an ultimate or yield moment $\left(M_{u}\right.$ and $M_{y}$ respectively) capacity that is less than the cracking moment capacity $\left(M_{c r}\right)$. A lower $M_{c r}$ than $M_{u}$ (or $M_{y}$ ) can result in the development of a single crack near the

72 base with all of the inelastic (plastic) behaviour concentrated at this location (Goldsworthy \& Gibson,

73 2012; Henry, 2013; Wibowo et al., 2013). The cracking moment capacity of an RC wall can be

74 calculated using the fundamental bending stress equation and incorporating the stress due to axial

75 load. This calculation is shown in Equation 1, where $f_{c t . f}^{\prime}$ is the characteristic flexural tensile strength

76 of concrete, $P$ is the axial load, $A_{g}$ is the gross section area, $t$ is the thickness of the wall and $L_{w}$ is the

77 length of the wall.

$M_{c r}=\frac{\left(f^{\prime}{ }_{c t . f}+\frac{P}{A_{g}}\right) t L_{w}{ }^{2}}{6}$

$78 \quad 1$

79 The characteristic flexural tensile strength of the concrete $\left(f_{c t . f}^{\prime}\right)$ is useful in determining a lower

80 bound for the moment at which flexural cracking first occurs. However, in the research being

81 conducted here, it is more important to determine a realistic value for the concrete flexural tensile

82 strength of the wall. The mean value of the flexure tensile strength of the concrete $f_{c t . f l}$ can be 
83 calculated using the equation from the Model Code 2010 (fib, 2010); the $f_{c t . f l}$ is related to the mean

84 value of the direct tensile strength of concrete $\left(f_{c t}\right)$, as shown in Equations 2-4. Note that $f_{c m i}$ is the

85 mean in situ compressive strength of concrete. An upper and lower bound of $f_{c t . f l}$ can be found by

86 multiplying $f_{c t}$ (Equation 3) by 1.32 and 0.68 respectively (fib, 2010; Standards Association NZ,

87 2006b).

$f_{c t . f l}=\frac{f_{c t}}{\alpha_{f}}$

$88 \quad 2$.

$f_{c t}=0.3\left(f_{c m i}\right)^{\frac{2}{3}}$

$89 \quad 3$

$\alpha_{f}=\frac{0.06 L_{w}{ }^{0.7}}{1+0.06 L_{w}{ }^{0.7}}$

904

91 It is important to note that in the case of the Pyne Gould building, concrete strengths of some concrete

92 structural elements were reportedly much higher than the specified 28-day cylinder strength $\left(f_{c}^{\prime}\right)$ value

93 specified in the design of 24.1 MPa and 17.2 MPa for the columns and beams; the columns had a

94 mean compressive strength $\left(f_{c m i}\right)$ of $47.3 \mathrm{MPa}$, while the beams had an $f_{c m i}$ of $40.7 \mathrm{MPa}$. The

95 increased strength factor, $\kappa$, defined as the ratio of the mean in situ compressive strength at the time of

96 testing (or of loading in the case of a building) to the specified characteristic strength of the concrete,

97 was found to be 2.0 and 2.4 for the columns and the beams respectively (Hyland, 2011). This factor is

98 'used to increase the concrete strength due to the initial variability in the concrete and increase of the

99 strength with age' (Hoult et al., 2015). Moreover, similar concrete testing by Holmes Solutions

100 (Smith \& England, 2012) of the failed RC wall in the Gallery Apartments building indicated that the

101 cylinder compressive strengths ranged from 46.5 $\mathrm{MPa}$ to $56 \mathrm{MPa}$, a corresponding increased strength

102 factor $(\kappa)$ of up to 1.86 for the $f_{c}^{\prime}$ of $30 \mathrm{MPa}$ used in design. Henry (2013) further suggests that even

103 when the ultimate moment capacity of the wall is significantly higher than the cracking moment

104 capacity, the plasticity can still be concentrated over a relatively short height of the wall. In this case 


$$
\sigma_{\text {crack }}=\frac{T}{A_{\text {eff }}}
$$


8

129 Using the calculations above, the "cracking stress ratio" can be calculated, which is the ratio of $\sigma_{\text {crack }}$

130 to $f_{c t . f l}$. If the cracking stress ratio $(c s r)$ is greater than or equal to 1 the wall has a sufficient amount of longitudinal reinforcement to allow secondary cracking. Rearranging Equations 5-8, and assuming the $\operatorname{csr}$ is equal to 1 , gives an equation for the minimum amount of longitudinal reinforcement to initiate secondary cracking $\left(\rho_{w v \text { min }}\right)$.

$$
\rho_{w v . \min }=\frac{\left(\mathrm{t}-n_{t} d_{b t}\right) f_{c t . f l}}{f_{u} t}
$$

1349

135 The longitudinal reinforcement ratio required to cause secondary cracking was calculated for typical 136 reinforced concrete wall parameters used in places of low-to-moderate seismicity. Mean and standard 137 deviation values for the material properties of the reinforcing steel were obtained from the study by Menegon et al. (2015) for the D500N bars which are commonly used in Australia. For the ultimate tensile strength $\left(f_{w}\right)$, the mean value is $660.5 \mathrm{MPa}$ and there is a standard deviation of $37.65 \mathrm{MPa}$. The mean, lower and upper characteristic values of $f_{u}$ were used in the calculations for finding the minimum longitudinal reinforcement ratio $\left(\rho_{w v . m i n}\right)$ for rectangular walls with a range of $f_{c m i}$ values, as illustrated in Figure 2(a). It should be noted that the mean value of $f_{c t . f l}$ has been used for calculations in deriving the values given in Figure 2(a). For the 3 metre wall used, it is assumed that all of the transverse and longitudinal reinforcement is distributed evenly in two grids. The wall thickness was assumed to be $200 \mathrm{~mm}$ and the longitudinal and transverse diameter reinforcing bars $\left(d_{b l}\right.$ and $\left.d_{b t}\right)$ were both $12 \mathrm{~mm}$. Varying the thickness of the wall, $t$, over the range of values typically used in practice had only a small influence on the $c s r$. Figure 2(a) illustrates that even for low levels of $f_{c m i}$ the $\rho_{\text {wv.min }}$ needed to cause secondary cracking is greater than the value of $0.15 \%$ specified in AS 3600 (Standards Australia, 2009). This minimum limit for reinforcement content is highly dependent on the assumed flexural tensile strength of the concrete $\left(f_{c t, f}\right)$, as is shown in Figure 2(b) when using mean, lower and upper characteristic values of $f_{c t . f l}$ (and a mean value for $f_{u}$ in all of these cases). For walls with $L_{w}$ of 3 metres, Equation 9 provides an estimate for the longitudinal reinforcement ratios of approximately $0.50 \%$ and $0.65 \%$ need to be utilised for $f_{c m i}$ values of $40 \mathrm{MPa}$ and $60 \mathrm{MPa}$ 
respectively if secondary cracks are to occur (where the mean values of the $f_{c t . f l}$ and $f_{u}$ are used). It should be noted that larger wall lengths will slightly decrease the reinforcement ratio required as the $f_{c t . f l}$ is reduced (Equation 4). However, this difference is negligible for the range of $L_{w}(3,6$ and 9 metres) being considered for this study. If secondary cracks are unable to form at the base of the wall then the plasticity will be limited to a very short length.

\section{Plastic Hinge Length}

The flexural displacement profile of a cantilever wall is typically the summation of two components: the yield displacement profile and the plastic displacement profile. $\mathrm{RC}$ walls with an aspect ratio greater than 2 are typically governed by flexural action, rather than shear mechanisms (Wibowo et al., 2013; Wood, 1989), with plastic behaviour at the base of the wall (it is assumed here that the longitudinal reinforcement is constant over the full height). The aspect ratio $\left(A_{r}\right)$ of the $\mathrm{RC}$ walls is defined in Equation 10, where $M / V L_{w}$ is the flexure-to-shear ratio.

$$
A_{r}=\frac{M}{V L_{w}}=\frac{H_{e}}{L_{w}}
$$

10.

where $M$ is the moment, $V$ is the shear and $H_{e}$ is the effective height of the wall.

To find the plastic deformations, the strains and corresponding curvatures need to be determined, and these will vary considerably up the height of a cantilevered wall. However, it is common practice to simply assume that the inelastic curvature is uniform for a height above the base that is equivalent to the plastic hinge length $\left(L_{p}\right)$ (Bohl \& Adebar, 2011; Fenwick \& Dhakal, 2007; Paulay \& Priestley, 1992; Priestley \& Park, 1987). This is a reasonable approximation and has been utilised by authors such as Priestley et al. (2007) in the equations given for the displacement profile of a cantilevered wall:

$\Delta_{i}=\Delta_{y}+\Delta_{p}=\frac{\varepsilon_{y} H_{i}^{2}}{L_{w}}\left(1-\frac{H_{i}}{3 H_{n}}\right)+\theta_{p} H_{i}$

11. 
178

179

180

181

182

183

184

185

186

187

188

189

190

191

where $\Delta_{y}$ and $\Delta_{p}$ are the yield and plastic displacements respectively, $\varepsilon_{y}$ is the yield strain, $H_{i}$ is the height of the wall at level $i, H_{n}$ is the height of the wall at roof level and $\theta_{p}$ is the plastic rotation.

$$
\theta_{p}=\left(\emptyset_{u}-\emptyset_{y}\right) L_{p}
$$

12.

where $\phi_{u}$ is the ultimate curvature and $\phi_{y}$ is the yield curvature.

The plastic hinge length and idealised curvature distribution are illustrated in Figure 3(a). The elastic curvature distribution is assumed to vary linearly up the cantilever wall, which tends to compensate for the increase in displacement due to tension shift effects and shear deformation (Priestley et al., 2007). Figure 3(b) illustrates the idealised expected steel strain distribution at ultimate condition (closest to the extreme tension fibre edge) of unconfined reinforced concrete walls that either form a single crack, or form a distribution of cracks up the wall height. It should be noted for the purpose of this study, as will be discussed later in Section 4.2, the ultimate concrete and steel strains for an unconfined RC section have been taken as 0.003 and 0.05 respectively. The wall with well distributed yielding in Figure 3(b) has lower steel strains, as expected, and is likely to fail in compression (concrete strains governing).

If a single, primary crack is formed in an RC wall, the strain penetration (or "yield penetration") length becomes the only source of plastic deformation (Morris et al., 2015). The strain penetration length is the depth that the inelastic strains of the reinforcing steel can penetrate (Patel et al., 2015). This length is shown in Figure 3(b), where the ultimate steel strain is reached in the extreme tension fibre region of the wall, with inelastic strains penetrating either side of the crack (into the wall and into the foundation). Therefore, the height over the wall in which yielding of the reinforcement occurs is severely reduced in comparison to a wall with distributed cracking, thus decreasing the $L_{p}$ that would be used in calculating the displacement capacity. As discussed in Morris et al. (2015), in this situation the elongation of the steel reinforcing bars is dependent on the amount the steel can strain and the true length of strain penetration either side of the primary crack. This dependency on the straining of steel reinforcement is particularly an issue for regions of low-to-moderate seismicity, where the uniform elongation strain $\left(\varepsilon_{s u}\right)$ of typical reinforcing bars (e.g. D500N bars in Australia) is 
204 low in comparison to bars used in regions of higher seismicity (e.g. D300E bars in New Zealand).

205 Recent field observations from the Christchurch earthquake in New Zealand indicated strain

206 penetration lengths into the foundation as low as 1 to $2 d_{b l}$ (Morris et al., 2015). As illustrated in

207 Figure 3(b), the plastic hinge length $\left(L_{p}\right)$ for walls with a single crack is approximately $2 L_{y p}$, where $L_{y p}$

208 is the strain penetration length measured on one side of the crack. Empirical equations are given later

209 in this section that make estimates of $L_{p}$ based solely on the strain penetration length.

210 There are many different empirical equations available for the plastic hinge length $\left(L_{p}\right)$ for situations

211 in which secondary cracking is expected to occur. Some of these equations, which will later be

212 scrutinised as to their applicability for lightly RC walls, include $L_{p}$ estimations from Bohl and Adebar

213 (2011) (Equation 13), Kazaz (2013) (Equation 14), Priestley et al. (2007) (Equation 15 and 16), ICBO

214 (1997) (Equation 17) and Thomsen and Wallace (2004) (Equation 18). It should be noted that

215 Equation 17 has been utilised in the 1997 Uniform Building Code (UBC) (ICBO, 1997) and more

216 recently in NZS 3101:2006 (Standards Association NZ, 2006a); it is a lower bound value that many

217 researchers have recommended (Moehle, 1992; Paulay, 1986; Priestley \& Park, 1984; Wallace \&

218 Moehle, 1992).

$$
L_{p}=\left(0.2 L_{w}+0.05 H_{e}\right)\left(1-\frac{1.5 P}{f_{c}^{\prime} A_{g}}\right) \leq 0.8 L_{w}
$$

21913.

220 where $A_{g}$ is the gross section area of the wall, $L_{w}$ is the wall length, $H_{e}$ is the effective height

221 (equivalent to $\mathrm{M} / \mathrm{V}$ ratio), $P$ is the axial load and $f_{c}^{\prime}$ is the compressive strength of concrete.

$L_{p}=0.27 L_{w}\left(1-\frac{P}{A_{g} f_{c}^{\prime}}\right)\left(1-\frac{f_{y} \rho_{w h}}{f_{c}^{\prime}}\right)\left(\frac{\frac{M}{V}}{L_{w}}\right)^{0.45}$

22214.

223 where $f_{y}$ is the yield strength of steel and $\rho_{w h}$ is the horizontal (transverse) reinforcement in the wall.

$$
L_{p}=k H_{e}+0.1 L_{w}+L_{s p}
$$


where $k$ is a constant reflecting the distribution of plasticity dependent on the ratio of the ultimate strength to yield strength of the reinforcing steel $\left(k=0.2\left(f_{u} / f_{y}-1\right) \leq 0.08\right), H_{e}$ is the effective height, and $L_{s p}$ is the strain penetration length defined as:

$$
L_{s p}=0.022 f_{y e} d_{b l}
$$

16.

$f_{y e}$ is the expected yield stress of the steel $\left(1.1 f_{y}\right)$.

$$
L_{p}=0.5 L_{w}
$$

17.

$L_{p}=0.33 L_{w}$

18.

However, these equations for the plastic hinge length have been derived from numerical or experimental results for $\mathrm{RC}$ walls that are not representative of lightly $\mathrm{RC}$ walls in regions of low-tomoderate seismicity. For instance, most of the experimental results that were used in deriving these equations were from tests on $\mathrm{RC}$ walls with well confined boundary regions and reinforcing steel with mechanical properties that would not be used in regions of low-to-moderate seismicity. Morris et al., (2015) emphasise the importance of the $f_{u} / f_{y}$ ratio in determining the extent of plasticity at the base of an RC wall. The importance of this has been recognised previously by other researchers, for example in Equation 15 for the $L_{p}$ estimation by Priestley et al. (2007). Strain hardening ratio $\left(f_{u} / f_{y}\right)$ values are given in Table 1 for reinforcing steel types that are common in Australia, types $\mathrm{L}$ and $\mathrm{N}$, as well as for type E which is commonly used in New Zealand. The lower characteristic values are obtained from the Australian Standard for steel reinforcing materials AS/NZS 4671:2001 (Standards Australia/New Zealand, 2001), while the mean values have been given in Menegon et al. (2015). The $f_{u} / f_{y}$ values for D500N reinforcing bars are lower than the 1.625 and 1.3 values used for plastic hinge length studies by Bohl and Adebar (2011) and Kazaz (2013) respectively. Both of these studies also focused on RC walls with a higher concentration of longitudinal reinforcement and confinement at the boundary ends than would be typically used in low-to-moderate seismic regions. 
248 It should be noted that the equations for $L_{p}$ determined by Equations 13-18 are known to be

249 approximate since although $L_{p}$ has been shown to be dependent on the axial load ratio $\left(A L R=P / f_{c}^{\prime} A_{g}\right)$

250 (Bohl and Adebar, 2011) these equations, with the exception of Equations 13 and 14, do not include

251 this variable.

252 A recent study by Altheeb et al. (2015) used scaled down experiments on lightly reinforced concrete

253 elements to derive a plastic hinge length (Equation 19) based on the strain penetration length from the

254 formation of a single crack.

$$
L_{p}=\frac{\left(f_{u}-f_{y}\right) d_{b l}^{1.2}}{4 \sqrt{f_{c}^{\prime}}}
$$

25519.

256 Wibowo et al. (2013) have proposed an alternative equation (Equation 20) for the plastic hinge length 257 for when $M_{c r}$ is larger than $M_{u}$ at the critical section in the RC walls. Wibowo et al. (2014) recognise 258 the possibility of a single crack forming for some lightly reinforced walls, consequentially reducing 259 'the plastic hinge length to a function of the yield penetration length'. $L_{p}=15 d_{b l}$ 26020.

261 As there is insufficient experimental data currently available to evaluate and develop empirical incorporate detailing that is typical of that used in low-to-moderate seismic regions, such as Australia.

\section{Equivalent Plastic Hinge Length}

In this study, the equivalent plastic hinge method has been adopted to investigate a series of walls that The Equivalent Plastic Hinge Length (EPHL) method has been used in past studies (Fenwick \& 
273 Dhakal, 2007; Henry, 2013; Mortezaei \& Ronagh, 2012) and has also been used to derive the plastic

274 hinge length and curvature limits set in NZS 3101 (Standards Association NZ, 2006a). The curvature

275 distribution up the the height of a cantilever wall can be used to determine the rotation at the base; as

276 is well known from the first moment area theorem, the rotation between two points up the the height

277 of the wall is equal to the area under the curvature distribution. Figure 3 illustrates that the curvature

278 distribution can be idealised into elastic and plastic regions, and likewise for the rotations. The

279 purpose of this study is to determine the extent of plasticity occurring at the wall base and hence to

280 estimate the plastic hinge length. Distributions of cracks and of the curvature have been obtained

281 using VecTor2 for a range of walls.

282

283 4.1 VecTor2 Model Validation

284 VecTor2 (Wong \& Vecchio, 2002) is a state-of-the-art nonlinear finite element modelling program for 285 plane RC sections that is based on the disturbed stress field model (DSFM) (Vecchio et al., 2000). VecTor2 has been used in a variety of past research for modelling RC walls (Beyer, 2007; Bohl \& Adebar, 2011; Dai, 2011; Ghorbani-Renani et al., 2009; Lu et al., 2014; Luu et al., 2013; Sritharan et al., 2014).

A range of material and constitutive models have been incorporated in VecTor2 to represent modelling of the concrete and steel materials. The Popovics normal-strength and the Popovics highstrength models were used for strengths up to $45 \mathrm{MPa}$ and higher than $45 \mathrm{MPa}$, respectively in accordance with recommendations from Palermo \& Vecchio (2007). The preliminary parameter studies conducted in Mohr (2007) suggested that the compression softening model that relies only on stress, rather than both stress and strain, gave better approximations at large displacements.

Therefore, Vecchio 1992-B (e1/e0-Form) (Vecchio, 1992) was chosen to model the compression softening of concrete. The Modified Bentz model (default) was used for the modelling of tension stiffening in the concrete. This model is essentially the same as the Bentz (1999) model for when 'the steel is aligned with the $\mathrm{x}$ or $\mathrm{y}$-axis (no skew steel)' (Bohl, 2003). The model is used in the Modified Compression Field Theory (MCFT) for programs such as Response-2000 (Bentz, 2000). Of the numerous bilinear models that are proposed by different researchers for the prediction of tension 
softening, the CEB-FIP (1990) model is utilised by VecTor2 and provides a bilinear model for the stress-strain relationship of concrete. Importantly, the default concrete fracture energy value of 75 $\mathrm{N} / \mathrm{m}$ has been used in VecTor2, which is a similar assumption to that used by other researchers (Bohl, 2003). The concrete hysteretic response was modelled with the Palermo option (Palermo \& Vecchio, 2002), as it has been shown to be a more suitable option for capturing the stiffness and overall behaviour in another study (Sagbas, 2007). The dilation model chosen for the lateral expansion of concrete is the 'Variable - Orthotropic' model (default), which is based on a Poisson's ratio that increases nonlinearly as the concrete compressive strain increases. The cracking criterion models estimate the decrease of cracking strength due to the increase of the transversely acting compressive stresses. The CEB-FIP Model is chosen specifically for the cracking criterion, which is based on a linear relationship proposed in Kupfer and Gerstle (1973). The compressive stresses of concrete elements close to cracks are required to be limited, mainly due to tensile strains in concrete close to cracks exceeding the calibration range of the compression softening models, which may permit additional softening. The crack width check reduces the average compressive stresses for when the crack width exceeds a set limit. The default was chosen ('Agg/2.5 Max Crack Width') as the limiting crack width. VecTor2 accounts for the strains due to shear slip along cracks with the element slip distortion models. The default model from Walraven (1981) was chosen for these calculations. The stress-strain curve from Seckin (1981) is used for the reinforcing steel. The Kupfer/Richart confinement model (Kupfer et al., 1969; Richart et al., 1928) was used even though unconfined walls have been considered in this study. It was found in earlier wall analyses using VecTor2, in which the enhancement due to confinement was turned off completely, that the compressive strains reached were unrealistically low. Professor F. Vecchio (personal communication, March 2, 2016) recommended the use of the Kupfer/Richart model, even though the concrete is unconfined, because it was likely to give a better representation of effects of phenomena such as lateral expansion. The actual strength enhancement factor incorporated as a result of using this model is very close to one in the case of walls without out-of-plane reinforcement, i.e. no enhancement. Bond-slip, using the Eligehausen (1983) model, was only considered for VecTor2 models that use truss and link elements to model the longitudinal reinforcement and bond behaviour respectively. For this model, the bond 
properties for the link elements were set to 'Embedded Deformed Rebars' with a Confinement

Pressure Factor of zero, corresponding to an unconfined case. For the other models, an assumption of perfect bond was assumed, as has been successfully adopted in other studies (Lu et al., 2015; Palermo \& Vecchio, 2007).

Very little experimental testing has been conducted on lightly reinforced unconfined RC walls.

Although Cardenas \& Magura (1972) tested a lightly reinforced concrete wall which formed a single crack, as discussed previously in Section 1, the experimental data for this wall is sparse and not ideal for the purposes of validation. The RC wall specimens R1 from Oesterle et al. (1976) and C1 from Lu et al. (2015) were deemed suitable for the purposes of validating the chosen material models that will be used in VecTor2.

\subsubsection{Wall R1 (Oesterle et al., 1976)}

The specimen R1 \{Oesterle, $1976 \# 484$ \} was a $4572 \mathrm{~mm}$ high, $1905 \mathrm{~mm}$ long $\left(h_{e} / l_{w}=2.4\right)$, and 102 $\mathrm{mm}$ thick RC wall that was subjected to reverse cyclic loading. The wall failed in flexure with fracturing of the reinforcement before crushing of the concrete. The longitudinal reinforcement consisted of two layers of $6 \mathrm{~mm}$ diameter longitudinal bars at a spacing of $229 \mathrm{~mm}$ in the web, while there was a concentration of $4 \# 3$ bars $\left(d_{b l}=9.525 \mathrm{~mm}\right)$ spaced at $140 \mathrm{~mm}$ at the boundary ends. Table 2 and Table 3 give the wall specimen details and the reinforcement properties respectively. A fraction of the reported uniform elongation strain of the steel $\left(\varepsilon_{s u}\right)$ was used due to the research findings by Wood (1989) that indicated the steel fractured at a reduced strain. A value of $0.6 \varepsilon_{s u}$ was adopted, as used by Priestley et al. (2007) to account for the possibility of low cycle fatigue. The wall specimen R1 was modelled in VecTor2 with the foundation block at the base, illustrated in Figure 4. Plane stress rectangular elements were used to model the concrete wall, which are fournoded elements with uniform thickness (Wong, 2002). The size of plane stress elements were within the $3: 2$ aspect ratio as recommended by Wong (2002). Palermo \& Vecchio (2007) further suggest that 14 - 16 elements are to be used in the short direction of the wall (parallel to the wall length) and this recommendation has also been adhered to, although a smaller mesh size, in the direction parallel to 
1

the wall length, was used to model some RC wall specimens at the boundary ends in order to facilitate the creation of nodes for discrete truss elements.

The longitudinal reinforcement was modelled using two different methods; (i) the bars were modelled using smeared reinforcement throughout the concrete plane stress rectangular elements and, (ii) the bars were modelled discretely using truss and link ("truss-link") elements. The second option including link elements was employed to model the behaviour of bond slip between the concrete and reinforcing bars. While the use of this option increased the number of nodes required in the model, this modelling option provided information on the strain penetration of the longitudinal reinforcing bars into the foundation. The sensitivity of the overall results to the inclusion of strain penetration needed to be investigated. Although the more computationally efficient smeared reinforcement approach has been shown in previous research to provide comparative results to those from analyses using truss elements in previous research (Beyer, 2007; Bohl \& Adebar, 2011; Ghorbani-Renani et al., 2009; Luu et al., 2013; Palermo \& Vecchio, 2007; Sritharan et al., 2014), no previous research is available that provides well correlated results for lightly reinforced concrete walls when comparing these two modelling decisions. Hence, it was decided to investigate this further in this study. Three different concrete materials were used, which consisted of different percentages of smeared reinforcement that were used to represent the different boundary, web and footing regions of the wall specimen. An axial load of $20.75 \mathrm{kN}$ was held constant during the analysis and was distributed along the nodes at the top of the wall section. The lateral loading applied to both models was monotonic and reverse cyclic (corresponding to the experimental testing) and was distributed evenly over all of the nodes at the top of the wall.

Figure 5 presents the force-displacement hysteresis results from VecTor2. The immediate observation is the reasonably well correlated predictions from VecTor2 in comparison to the experimental results from Oesterle et al. (1976) for the wall being subjected to either reverse cyclic or monotonic loading. Moreover, there is a good correlation between the results using smeared reinforcement in Figure 5(a) and the results using the discrete truss-link elements in Figure 5(b). The flexural strengths predicted by VecTor2, using the values for the concrete and reinforcement properties from the testing by Oesterle et al. (1976), are slightly overestimated. However, this observation was to be expected as it 

was also observed by Oesterle et al. (1976), who stated 'the observed strengths were somewhat lower than the flexural strengths calculated using measured material properties including strain hardening in the reinforcement'. For example, the maximum force that was predicted by VecTor2 from all of the models and loading conditions considered was $146.2 \mathrm{kN}$, whereas the maximum measured load from Oesterle et al. (1976) for R1 was $118.3 \mathrm{kN}$. This correlated with the observations from Oesterle et al. (1976), where the maximum observed experimental force of all the specimens tested varied from $77 \%$ to $91 \%$ of the flexural capacities that they had calculated. The sharp drop in strength in both of the smeared and truss models for monotonic loading corresponded to the ultimate strain being reached or exceeded $\left(0.6 \varepsilon_{s u}=58.8 \mathrm{~mm} / \mathrm{m}\right)$ at either the extreme tension fibre edge or the closest truss element to the tension edge respectively. There was a difference of displacement capacity for the walls modelled using smeared reinforcement compared to the model that used truss-link elements; displacements of $108 \mathrm{~mm}$ and $91 \mathrm{~mm}$ (for monotonic loading) corresponded with the outermost longitudinal reinforcing bars reaching or exceeding $0.6 \varepsilon_{s u}$ for the smeared and truss-link models respectively. The first observations by Oesterle et al. (1976) of a reinforcing bar fracturing occurred in cycle 26, which corresponded with one of the outermost bars at a displacement of around $101 \mathrm{~mm}$. This experimental observation compares well to the displacement capacity estimated in VecTor2. It should be noted that the ultimate strain used in VecTor 2 is $60 \%$ of the uniform elongation strain value reported by Oesterle et al. (1976) from the monotonic material tests. The reduced value was used to account for low cycle fatigue effects and this reduced ultimate strain limit has led to a good comparison between the predicted and observed displacement capacity.

VecTor2 was able to predict the force-displacement performance of the lightly reinforced wall specimen R1. However, for the purposes of studying the equivalent plastic hinge length $\left(L_{p}\right)$, it is important that VecTor2 is able to predict the tension strain distribution up the wall height. Figure 6 and Figure 7 present the tension strains in the steel from VecTor 2 for the smeared and truss-link models respectively. The strains are presented as discrete values since these are average strain values across the element height (plotted at the centre of each element). Superimposed in these figures are the strain distributions as given in Oesterle et al. (1976) at several different levels of displacement at the top of the wall. It is important to note that the strain gauges attached to the reinforcing steel bars 
412 in the experiment by Oesterle et al. (1976) for wall specimen R1 debonded between a strain of 15

$413 \mathrm{~mm} / \mathrm{m}$ and $30 \mathrm{~mm} / \mathrm{m}$. Hence, the strain reading from the experiment is limited to $12.5 \mathrm{~mm} / \mathrm{m}$ in many

414 of the readings for the higher displacements so there is a limited scope for comparison between the

415 experimental and the finite element results. It is noted here that the strain distribution from the 416 experimental results at a displacement at the top of the wall of $101 \mathrm{~mm}$ is compared with the VecTor2

417 truss-link results at the ultimate displacement predicted by VecTor2 of $91 \mathrm{~mm}$.

418 Overall, at locations where comparisons are able to be made, there is a good fit between the strains 419 predicted in VecTor2 and the observations from the experiment. The VecTor2 results provide a good 420 fit to the available data for the higher lateral displacements. For the strain distributions at the final displacement, the smeared reinforcement model results from VecTor2 give as good a match, or better, to the experimental data when compared with the truss-link results. It was experimentally observed that the yielding zone $\left(\varepsilon_{s y} \approx 2.67 \mathrm{~mm} / \mathrm{m}\right)$ only occurred in the lower $1.83 \mathrm{~m}$ of the wall (Oesterle et al, 1976), and the smeared reinforcement model predicts this well (Figure 6c). However, the truss-link model had a longer "yield zone", with larger strains than that observed experimentally (Figure 7c). Moreover, these strains for the truss-link model occurred at a smaller displacement $(91 \mathrm{~mm})$ of the wall compared to the displacement $(101 \mathrm{~mm})$ that corresponded to the experimentally captured strains. These results indicate that the VecTor2 model that uses smeared reinforcement gives results with a similar degree of accuracy to those obtained using the VecTor2 model with truss elements. Importantly, the steel strain into the foundation was small for the model that utilised discrete trusslink elements. For example, the highest average steel strain into the foundation estimated by VecTor2 was found to be $1.096 \mathrm{~mm} / \mathrm{m}$. This strain is small when compared with the average strain reached in the element just above the foundation of $43.5 \mathrm{~mm} / \mathrm{m}$ at the same displacement $(91 \mathrm{~mm}$, Figure $7 \mathrm{c}$ ) for the same discrete reinforcing bar. Moreover, given that these strains are less than the approximate yield strain $\left(\varepsilon_{s y}\right)$ of $2.66 \mathrm{~mm} / \mathrm{m}$, the strains below the foundation are likely to make little contribution to the plastic hinge length. Insignificant strains into the foundation were also observed by Kazaz (2013) for all of the walls analysed using a different finite element program. A similar situation was also observed by Bohl \& Adebar (2011). This analytical observation suggests that modelling the foundation block is unnecessary in VecTor2 for the purposes of calculating the effective plastic hinge 
440 length. Modelling the foundation is particularly unnecessary if smeared reinforcement is to be used to

441 model the longitudinal reinforcement. Hence in the study, the foundation block was ignored as the

442 elements were modelled as smeared elements. Neglecting to model the foundation block was also

443 followed in the analyses reported in Bohl (2003) in which the foundation block was not included in

444 the models when using VecTor2 to calculate plastic hinge lengths.

445 Strain distributions across the wall are also important in the calculation of curvature. As mentioned

446 previously, due to debonding of the strain gauges at large wall displacements, no relevant data is

447 available for the vertical strains at the base of the wall. However, vertical strains at $3 \mathrm{ft}(914.4 \mathrm{~mm})$

448 from the base of the wall corresponding to a displacement at the top of the wall of $51 \mathrm{~mm}$ are

449 available (Oesterle et al., 1976). Importantly, this was within the 'yielding zone'. Figure 8 presents

450 the strain distribution together with the superimposed VecTor2 results at the same height of the wall.

451 The estimated strain values across the cross section from VecTor2 correspond well to the

452 experimentally observed strains from Oesterle et al. (1976).

453 It is important that VecTor2 is able to accurately predict the distribution of cracks in the wall. Figure

4549 compares the experimentally observed cracking pattern for the lower 1.83 metre of specimen R1

455 Oesterle et al. (1976) to the VecTor2 predictions (smeared model, monotonic loading) at a

456 displacement at the top of the wall of $76 \mathrm{~mm}$. The cracking patterns are similar, with the lower 0.91

457 metre of the wall 'completely traversed by several predominately horizontal cracks' (Oesterle et al.,

458 1976). Although this wall specimen is considered to be lightly reinforced, a number of cracks have

459 formed at the base of the wall. If the longitudinal reinforcement ratio in the web of R1 (Table 2) was

460 used in the secondary cracking model introduced in Section 2, there would be an indication that this

461 wall would not have sufficient reinforcement to initiate secondary cracking. However, the area of

462 reinforcement that is lumped at the boundary ends is sufficient to produce a locally higher

463 reinforcement ratio which generates the observed well distributed cracks.

464 The VecTor2 predictions of the performance of wall specimen R1 (Oesterle et al., 1976), with the

465 chosen material models, has been shown to compare reasonably well to the relevant experimental

466 data. Moreover, similar validation is carried out for another lightly reinforced wall specimen C1 from

467 Lu et al. (2015). 


\subsubsection{Wall C1 (Lu et al., 2015)}

470 Lu et al., 2015 reported on an experimental program which was conducted to evaluate the seismic 471 performance of RC walls with minimum longitudinal reinforcement in accordance with NZS 3101

472 (Standards Association NZ, 2006a). The wall specimen C1, with cross-section shown in Figure 10, 473 was designed to represent a $50 \%$ scale of a multi-story flexure-dominant RC wall with limited 474 ductility (Lu et al., 2015) and was tested under reverse cyclic conditions. Following the same 475 approach as that in Section 4.1.1, two different methods of modelling the longitudinal reinforcement 476 in VecTor2 were undertaken; Model 1 which uses smeared reinforcement and Model 2 which uses 477 discrete truss elements with link elements (truss-link). The strain distribution at $1.5 \%$ drift (top wall 478 displacement of $42 \mathrm{~mm}$ ) was also reported in Lu et al. (2015), and this will be compared to the 479 VecTor2 results at the same lateral drift.

480 Figure 11(a) illustrates the mesh and element setup for Model 1. The foundation block at the base 481 was assumed to be $500 \mathrm{~mm}$ x $1820 \mathrm{~mm}$ (x $350 \mathrm{~mm}$ high). The concrete compressive strength was $482 \quad 38.5 \mathrm{MPa}$, while the tensile strength of the concrete was $2.88 \mathrm{MPa}$. The yield and ultimate stress of 483 the $10 \mathrm{~mm}$ diameter longitudinal reinforcing bars were $300 \mathrm{MPa}$ and $409 \mathrm{MPa}$ respectively. The 484 ultimate strain was taken as $0.6 \varepsilon_{s u}$ as discussed previously in Section 4.1.1, which is approximately 92 $485 \mathrm{~mm} / \mathrm{m}$ in this case. Model 2, which utilises the link elements, uses the Eligehausen (1983) concrete 486 bond model to predict the amount of strain penetration into the foundation, the same approach as that 487 used previously when modelling wall specimen R1 in Section 4.1.1. In both models the horizontal 488 reinforcement was modelled with smeared reinforcement. A total axial load of $294 \mathrm{kN}(A L R=3.5 \%)$ 489 was uniformly distributed to all nodes at the top of the wall (held constant throughout the analysis), 490 while the same nodes were subjected to a lateral displacement for both the monotonic or reverse 491 cyclic loading scenarios.

492 Figure 12 presents the results from VecTor2 for both monotonic and reverse cyclic conditions for 493 Model 1 (smeared) and Model 2 (truss-link). Superimposed on these figures are the experimental 
494 results from Lu et al. (2015). The results from VecTor2 match well with the force-displacement

495 hysteresis observed experimentally.

496 Figure 13 presents the strain distribution results in the steel from VecTor2 at the extreme fibre edge of 497 the wall in tension for Model 1 (smeared) and Model 2 (truss-link). Superimposed on this figure are 498 the strain distributions recorded by Lu et al. (2015). The strain distributions predcicted by VecTor2 499 for Model 1 (smeared) in Figure 13(a) correlate well with the experimental observations.

500 Furthermore, the strains predicted with cyclic loading did not differ much from the predictions with 501 the wall subjected to monotonic loading, which was an observation also reported by Hannewald 502 (2013). Model 2 (truss-link) predicts a similar steel strain distribution up the wall height as shown in 503 Figure 13(b). However, this model (truss-link) over predicts the steel strains in comparison with the 504 experimental observations from Lu et al. (2015) and also when compared with Model 1 (smeared) shown in Figure 13(a). Model 2 (truss-link), which uses the Eligehausen (1983) bond model, also predicts a higher steel strain into the foundation in comparison to Model 1 (smeared). For example, the strains of the truss elements into the foundation at the extreme tension fibre edge of the wall for Models 1 and 2 were found to be $0.002 \mathrm{~mm} / \mathrm{m}$ and $0.504 \mathrm{~mm} / \mathrm{m}$ respectively at a top displacement of the wall of $42 \mathrm{~mm}$. However, these strain values were deemed to be insignificant in comparison to the strains predicted by VecTor2 just above the foundation. Insignificant strains into the foundation were similarly observed for the truss-link elements model used to simulate the performance of wall specimen R1 (Oesterle et al., 1976) in Section 4.1.1. Furthermore, the strains predicted by Model 2 with the truss-link elements into the foundation did not reach yield $\left(\varepsilon_{s y} \approx 2.00 \mathrm{~mm} / \mathrm{m}\right)$ throughout the analysis $(1.28 \mathrm{~mm} / \mathrm{m}$ at a top displacement of $70 \mathrm{~mm})$.

Overall, VecTor2 has been shown to provide well correlated results to the experimental observations from wall specimens R1 (Oesterle et al., 1976) and C1 (Lu et al., 2015). Importantly, the strain distributions up the wall height are well correlated, particularly for the VecTor2 model that uses smeared reinforcement. Although the reliability of experimental strain data captured from strain gauges is questionable, the VecTor2 results corroborate well with the available strain data from the two experimental walls analysed here, both of which relied upon strain gauges. The VecTor2 results 
of the strains into the foundation using truss-link elements is questionable considering the small strain value achieved by the finite element modelling program in comparison to the expected yielding of reinforced bars over some length into the foundation. However, as mentioned in Section 3, recent observations have revealed strain penetration lengths (into the foundation) that are as low as $1.0 d_{b l}$. Therefore, numerical analyses have been conducted on walls representative of those found in regions of low-to-moderate seismicity, adopting a conservative approach in VecTor2 to calculate the effective plastic hinge length; smeared reinforcement, which assumes perfect bond, will be used in the subsequent VecTor2 analyses. Consequently, the calculated $L_{p}$ using the EPHL method (Section 4) does not include plasticity from the strain penetration into the footing, similar to the method used in the plastic hinge length study by Kazaz (2013).

\subsection{VecTor2 Analyses for Lightly Reinforced Walls}

In total, 378 lightly RC walls with varying parameters have been analysed in VecTor2 for calculation of plastic hinge length. The range of parameters considered in VecTor2 is summarised in Table 4. The effective height $\left(H_{e}\right)$ is estimated to be $0.7 H_{n}$ as recommended by Priestley et al. (2007) and all of the walls' aspect ratios are greater than 2 (governed by flexure). The ALRs have been chosen to represent the majority of the building stock in low-to-moderate seismic regions, where ALRs of less than $5 \%$ are common in walls with low vertical reinforcement (Henry, 2013). Moreover, the RC walls investigated by Albidah et al. (2013) for low-to-moderate seismic regions indicated that most of the walls had ALRs less than 5\%, and the highest ALR did not exceed 10\%. The longitudinal reinforcement ratio $\left(\rho_{w v}\right)$ was varied between 0.15 to $1 \%$, which has been said to 'represent the great majority of building stock in low-to-moderate seismic regions such as Australia' (Wibowo et al., 2013). The two $f_{c m i}$ values of the walls considered in this study were $40 \mathrm{MPa}$ and $60 \mathrm{MPa}$, which are realistic values for walls designed originally with a characteristic compressive strength $\left(f_{c}^{\prime}\right)$ of $32 \mathrm{MPa}$ and $40 \mathrm{MPa}$, given that the target strength would have been higher than this and that the concrete strength will increase with time. The $f_{c m i}$ values adopted correspond to $\kappa$ values of 1.25 and 1.50 respectively; these are values representative of concrete that has aged over several years as indicated in Moehle (2015). Mean values of the material properties for the reinforcing steel were adopted from 
549 Menegon et al., (2015) for D500N bars which conform to AS/NZS 4671 (Standards Australia/New

550 Zealand, 2001). The $f_{y}$ used was $551 \mathrm{MPa}$ with an $E$ of $200,000 \mathrm{MPa}$ and $f_{u} / f_{y}=1.20$. The ultimate

551 strain for the purpose of the wall assessments was taken as $60 \%$ of the mean value of the uniform

552 elongation strain, i.e. $0.6 \varepsilon_{s u}(0.6 \times 94.6 \mathrm{~mm} / \mathrm{m}=57 \mathrm{~mm} / \mathrm{m})$, based on the recommendations from

553 Priestley et al. (2007) as discussed previously in Section 4.1.1.

554 A refined mesh size was used for the lower section of the walls (over a height of $L_{w}$ ), whereas the

555 rectangular elements above this predicted "yielding zone" had an incrementally increasing vertical

556 mesh size to reduce the number of nodes and elements required. The resize of mesh decreased the

557 computation time while improving the accuracy of cracking distributions (vertically and horizontally)

558 at the base of the wall. This approach has been used successfully by other researchers (Bohl \&

559 Adebar, 2011). In order to capture the expected highly localised strains in a single crack, a minimum

560 element size corresponding to $0.5 t$ was adopted for the walls, which was similar to the sizing of the

561 elements used to validate VecTor2 in Section 4.1. The 3:2 aspect ratio recommendation by Wong

562 (2002) for the plane stress elements was adhered to for the "yielding zone" of the wall. The axial load

563 on the wall was held constant throughout the analyses, whereas the lateral displacement was monotonically increased at the top of the wall $\left(H_{e}\right)$ until failure. Curvature distributions were obtained when the strains in either the concrete or steel reached the strain values corresponding to the "collapse prevention" limit state. An unconfined concrete strain value of $0.003(0.3 \%)$ and steel strain value of $0.05(5 \%)$, were used to represent the collapse prevention limit state for an unconfined concrete wall with N-type longitudinal reinforcement. The equivalent plastic hinge length $\left(L_{p}\right)$ was calculated using the equivalent plastic hinge length method discussed previously in Section 4.

Results for the $L_{p}$ as a function of the $\rho_{w v}$ range used for each wall are shown in Figure 14(a) and (b) for $f_{c m i}$ values of $40 \mathrm{MPa}$ and $60 \mathrm{MPa}$ respectively. Superimposed in these figures (red square-dot line) are indications of the respective $\rho_{w v \text { min }}$ calculated from the secondary cracking model presented in Section 2. The $\rho_{w v \text { min }}$ from the secondary cracking model clearly gives a good prediction of the onset of secondary cracking and consequently of distributed plasticity. For the walls with $\rho_{w v}$ less than $\rho_{w v \text { min }}$, a small $L_{p}$ can be observed, corresponding to strains being concentrated at a single, primary crack. Similarly, Figure $15(\mathrm{a})$ and (b) show the $L_{p}$ results as a function of the ratio of the 
ultimate moment capacity $\left(M_{u}\right)$ to the cracking moment $\left(M_{c r}\right)$ of the walls for $f_{c m i}$ values of $40 \mathrm{MPa}$ and $60 \mathrm{MPa}$ respectively. It should be noted that $M_{c r}$ has been calculated from Equation 1 using the mean flexural tensile strength $\left(f_{c t . f f}\right)$ value rather than the characteristic flexural tensile strength $\left(f^{\prime}{ }_{c t . f}\right)$ value. It is shown that a ratio of $M_{u} / M_{c r}$ of about 2.0 is needed to achieve a good distribution of inelastic behaviour. This is larger than the $1.2 M_{c r}$ that is required when designing beams in accordance with AS 3600 (Standards Australia, 2009), and by implication for the design of some RC walls, as suggested by Beletich et al. (2013). Paulay and Priestley (1992) have recommended that minimum reinforcement to provide an ultimate capacity of at least $1.5 M_{c r}$ be used and Morris et al. (2015) further suggests 1.5 to 2.0 times $M_{c r}$ be used, the latter of which appears to agree with the VecTor2 results.

As expected, for walls in which distributed plasticity does occur, the length of the plastic hinge zone is limited by the low value of the ultimate strain in compression for unconfined concrete $(0.003)$. In Figure 16, it is shown that for walls that have a $\rho_{w v}$ higher than $\rho_{w v . m i n}$, the ultimate concrete strain governs rather than the steel tensile strain limit.

\section{Plastic Hinge Lengths for Lightly Reinforced Walls}

As shown in Figure 14, a significant $L_{p}$ is achieved for walls that have a reinforcement ratio greater than $\rho_{w v \text { min }}$ with a plateau approximately being achieved for most walls after $1.2 \rho_{w v \text { min }}$, where $\rho_{w v \cdot \text { min }}$ is calculated using the secondary cracking model from Section 2 . In contrast, the $L_{p}$ is much smaller and reasonably insensitive to the parameters for walls with $\rho_{w v}$ less than $\rho_{w v . m i n}$ due to the formation of a single-crack. Therefore, only the $L_{p}$ results for walls with a longitudinal reinforcement content greater than $1.2 \rho_{w v . \text { min }}$ will be used to derive a plastic hinge length equation (in total, 162 walls); a low, constant value will provide an adequate representation of the plastic hinge length for the walls with reinforcement ratios less than $\rho_{\text {wv.min }}$. Using the results, Figure 17 shows the calculated effective plastic hinge length $\left(L_{p}\right)$ normalised to the respective wall length $\left(L_{w}\right)$ is plotted against various wall design parameters. These three key parameters $\left(L_{w}, A L R\right.$ and $\left.a\right)$ have previously been observed to influence the spread of plasticity in the wall (Kazaz, 2013). However, as illustrated in Figure 17(a), in the case of the walls analysed here, the wall length $\left(L_{w}\right)$ had less of an influence on the plastic hinge 
length than previous research would indicate (Bohl \& Adebar, 2011; Kazaz, 2013). In contrast, the axial load had a greater effect on reducing the plastic hinge length in the walls in comparison to that reported in other research (Kazaz, 2013). This is most likely a result of the lower concrete strain capacity in comparison to walls that had been designed for seismic loading (with confinement). As illustrated in Figure 17(b), higher axial loads subject the wall to larger concrete stresses (and strains), thus leading to the strain capacity of the concrete $(0.003)$ being reached at lower displacements. The aspect ratio $\left(A_{r}=M / V L_{w}=H_{e} / L_{w}\right)$ of the wall increases the spread of plasticity, as shown with the

612 correlation found in Figure 17(c).

613 A multiple linear regression analysis was used to derive the plastic hinge length expression for 614 unconfined lightly reinforced concrete rectangular walls (Equation 25).

$$
L_{p}=\left(0.10 L_{w}+0.075 H_{e}\right)\left(1-6.0\left(\frac{P}{A_{g} f_{c m i}}\right)\right) \leq 0.5 L_{w}
$$

25.

616 The maximum limit of $0.5 L_{w}$ used here is the same as that proposed by many authors, as discussed in

617 Section 3. It is clear in Figure 17 that very few walls in this study surpassed this limit. Using the

618 standard errors calculated from the multiple linear regression analysis for each of the relevant

619 parameters, Equation 26 was derived to represent a lower bound estimate of $L_{p}$ (mean minus two

620 standard deviations).

$$
L_{p}=\left(0.05 L_{w}+0.050 H_{e}\right)\left(1-5.5\left(\frac{P}{A_{g} f_{c m i}}\right)\right) \leq 0.5 L_{w}
$$

62126

622 It is recommended that Equation 26 be used for design purposes when calculating the displacement capacity of unconfined lightly reinforced concrete rectangular walls commonly used in low-tomoderate seismic regions which have a vertical reinforcement ratio greater than $1.2 \rho_{w v . m i n}$. On the

625 other hand, Equation 25 can be used for assessment purposes since it provides a more realistic and 626 less conservative value.

627 Figures $18(\mathrm{a}-\mathrm{e})$ plot the VecTor 2 results for $L_{p}$ (for walls with $\rho_{w v}$ greater than $1.2 \rho_{w v \cdot m i n}$ ) against the $L_{p}$ 628 estimates from the expressions introduced in Section 3 (Equations 13 - 18). The majority of these 
1

expressions overestimate the $L_{p}$ for the lightly reinforced, unconfined RC walls analysed in this study. Not surprisingly, the expression derived in this study (Equation 25), plotted (black circles) in Figure 18(f), gives the result with the best correlation $\left(\mathrm{R}^{2}=0.87\right)$. The results using the lower bound $L_{p}$ expression from Equation 26 are also plotted in Figure 18(f) (red-broken circles) and the use of this equation is shown to provide a lower bound to the predictions from VecTor2.

For walls that are likely to exhibit a single-crack failure a conservative value of $L_{p}$ is warranted for use in design due to the brittle nature of these walls. The mean $(\mu)$ and standard deviation $(\sigma)$ of $L_{p}$ for the 3, 6 and 9 metre walls with a $\rho_{w v}$ less than or equal to the corresponding $\rho_{w v . m i n}$ were calculated and are given in Table 5. However, it should be noted that these values in Table 5 have been obtained from VecTor2 models that use smeared reinforcement and therefore perfect bond was assumed. It has been shown previously by Priestley and Park (1984) that the deterioration of the bond strength between the concrete and reinforcing bar will increase the strain penetration length. Therefore, a constant value of $100 \mathrm{~mm}$ represents a conservative estimate of the lower bound plastic hinge length for single-crackfailure walls. Nevertheless, Equations 16, 19 and 20 from Section 3, which all attempt to include the effects of strain penetration into the foundation, estimate $L_{p}$ values of $145 \mathrm{~mm}, 70 \mathrm{~mm}$ and $150 \mathrm{~mm}$ respectively, which are similar to the value proposed here. These estimates will all lead to low values for the displacement capacity of walls with a single crack at the base. The use of a conservative value is warranted due to the potentially brittle failure mode.

\section{Validation of proposed Plastic Hinge Length equation}

Recent experimental testing on rectangular $\mathrm{RC}$ wall elements has provided an opportunity to compare the proposed plastic hinge length $\left(L_{p}\right)$ equation (Equation 25) to experimental observations. Albidah (2016) and Altheeb (2016) conducted experimental testing for seismic performance of three lightly reinforced concrete rectangular walls; two of these three walls (W1 and W2) had parameters which conformed to the limitations of the proposed plastic hinge length equation and values used in the numerical study given in Section 4.2. Importantly, the walls had detailing typical of that used in the low-to-moderate seismic region of Australia and also incorporated D500N reinforcing bars as the 
longitudinal reinforcement. The N-type steel is commonly used in Australia and has normal ductility (as opposed to E type steel that is used in regions of high seismicity and has greater ductility). The details for the walls are given in Table 6 while the cross-sections are shown in Figure 19. The mechanical properties of steel for both walls are given in Table 7.

Wall specimen 1 (W1) had a $\rho_{w v}$ of $0.33 \%$, lower than the estimated $\rho_{w v \cdot m i n}$ of $0.47 \%$ (using Equation 9). The experimental observations from Altheeb (2016) indicate that two primary cracks formed during the cyclic loading, with the larger crack at the base extending to approximately $9.8 \mathrm{~mm}$ from the edge of the wall for a top wall displacement of $50 \mathrm{~mm}$. At a top wall displacement of $70 \mathrm{~mm}$, fracturing of the outermost longitudinal reinforcing bars occurred, confirming that the strain in the steel had been concentrated at the primary crack at the base. The damage states of the wall at these displacements are shown in Figure 20. Altheeb (2016) concluded that the performance of wall specimen W1 was primarily governed by strain penetration deformations. These results are consistent with the secondary cracking model (SCM) that has been introduced in Section 2 and indicate that Wall W1 had an insufficient amount of longitudinal reinforcement to allow secondary cracking. Wall specimen 2 (W2) had a longitudinal reinforcement ratio of $0.66 \%$, which is higher than the estimated $\rho_{w v \cdot \min }$ of $0.47 \%$. Albidah (2016) and Atheeb (2016) observed that W2 was influenced more by its flexural response in comparison to W1. The curvature distribution at a top wall displacement of $80 \mathrm{~mm}$ for $\mathrm{W} 2$ is shown in Figure 21. These curvature values were calculated based on measurements from string potentiometers (Albidah, 2016; Altheeb, 2016). This curvature distribution can be used in conjunction with the EPHL method (Section 3) to calculate the equivalent plastic hinge length $\left(L_{p}\right)$. Using a yield curvature $\left(\phi_{y}\right)$ value of $5.6 \mathrm{rad} / \mathrm{km}$, the resulting $L_{p}$ is estimated to be 235.5 $\mathrm{mm}$, as indicated in Table 8. Following this, the estimated $L_{p}$ from the experimental results is compared to calculated values from the range of plastic hinge length equations given in Section 3, as well as the $L_{p}$ equation proposed in this study (Equation 25). Table 8 shows that not only does the proposed $L_{p}$ equation (Equation 25) result in the closest length to the experimentally obtained value, but it is also the only one that underestimates the plastic hinge length, i.e. the only conservative estimate. 
683

\section{Conclusion}

The aim of this research was to derive a plastic hinge length equation suitable for the assessment of the lightly reinforced concrete walls that are commonly used in low-to-moderate seismic regions such as Australia and to compare this with existing equations. A minimum longitudinal reinforcement ratio $\rho_{w v \cdot \min }$ was found to be necessary to initiate secondary cracking at the base of the wall. It can be estimated using the secondary cracking model introduced in Section 2. This minimum longitudinal reinforcement ratio was found to be much larger than the minimum that is currently stipulated in some provisions, including AS 3600 (Standards Australia, 2009). It was shown in Section 5 that the empirical plastic hinge length equations that are commonly used in the displacement-based design and assessment are inappropriate for lightly reinforced walls. Expressions for the plastic hinge length have been derived from an extensive numerical study and are given as follows:

$L_{p}=100 \mathrm{~mm}$ for $\rho_{w v}<\rho_{w v \cdot \min }$

$L_{p}=\left(0.10 L_{w}+0.075 H_{e}\right)\left(1-6.0\left(\frac{P}{A_{g} f_{c m i}}\right)\right) \leq 0.5 L_{w}$ for $\rho_{w v} \geq \rho_{w v . m i n}$

For $\rho_{w v}<\rho_{w v . m i n}$, the constant value of $100 \mathrm{~mm}$ will give a conservative estimate of the plastic hinge length for walls that fail due to brittle fracture of longitudinal steel bars at a single crack at the base of the wall.

There are some limitations on the use of the equations due to the range of parameters used to derive them; it is important to determine, for instance, whether it provides reasonable results for larger values of $L_{w}$ and $H_{e}$ than those used in this study. Equation 25 and 26 are specific to rectangular, unconfined $\mathrm{RC}$ walls with distributed longitudinal reinforcement and a longitudinal reinforcement ratio upper limit of $1 \%$. The axial load ratio is limited to $10 \%$, the maximum value used in this study. The aspect ratio of the walls should be equal to or greater than 2 , since the behaviour of the $\mathrm{RC}$ wall will be governed by flexural actions in this case. As discussed in Section 3, the $f_{u} / f_{y}$ ratio will also have an influence on the spread of plasticity. Therefore, the derived $L_{p}$ equation is also limited to walls with $\mathrm{N}$-type reinforcement. However, it is possible that the $L_{p}$ equation derived will give a conservative result (with the exception of L-type reinforcing steel) for unconfined and lightly reinforced walls with 
other types of reinforcing bars, considering that N-type reinforcing typical has a low $f_{u} / f_{y}$ value in

711

712

713

714

715

716

717

718

719

720

721

722

723

724

725

726

727

728

729

730

731

732

733

734

735

736

737

738

739

740

741

742

743

744

745

746

747

748

749

750

751

comparison to other types used in high seismic regions. This research has highlighted the

vulnerability of lightly reinforced rectangular RC walls in low-to-moderate seismic regions. Further

research on the plastic hinge length for lightly reinforced concrete walls is warranted and an

experimental program is currently being conducted as part of the CRC project.

\section{Acknowledgements}

The support of the Commonwealth of Australia through the Cooperative Research Centre program is acknowledged.

\section{References}

ABCB. (2007). Final Regulation Impact Statement for Decision - Proposal to Amend the Earthquake Provisions of the Building Code of Australia.

Albidah, A., Altheeb, A., Lam, N., \& Wilson, J. (2013). A Reconnaissance Survey on Shear Wall Characteristics in Regions of Low-to-Moderate Seismicity. Paper presented at the Paper presented at the Australian Earthquake Engineering Society 2013 Conference, Hobart, VIC. Albidah, A. (2016). Vulnerability and Risks of Collapse of Structural Concrete Walls in Regions of Low to Moderate Seismicity. (Doctor of Philosophy), The University of Melbourne.

Altheeb, A., Albidah, A., \& Lam, N. (2015, 6-8 Novemeber, 2015). Analytical modelling of strain penetration deformation in reinforced concrete members. Paper presented at the Proceedings of the Tenth Pacific Conference on Earthquake Engineering, Sydney, Australia.

Altheeb, A. (2016). Seismic Drift Capacity of Lightly Reinforced Concrete Shear Walls. (Doctor of Philosophy), The University of Melbourne.

Beletich, A. S., Hymas, I. D., Reid, S. G., \& Uno, P. J. (2013). Reinforced concrete : the designers handbook: Baulkham Hills, N.S.W. Cement and Concrete Services, 2013.

Bentz, E. C. (1999). Sectional Analysis of Reinforced Concrete Structures. (PhD), University of Toronto, Toronto, Ontario.

Bentz, E. C. (2000). RESPONSE-2000: Sectional Analysis of Reinforced Concrete Members (Version 1.0.5). University of Toronto. Retrieved from http://www.ecf.utoronto.ca/ bentz/r2k.htm

Beyer, K. (2007). Seismic design of torsionally eccentric buildings with U-shaped RC Walls. (PhD), ROSE School. (ROSE-2008/0X)

Bohl, A. (2003). Plastic Hinge Length in High-Rise Concrete Shear Walls. (Masters of Applied Science), The University of British Columbia.

Bohl, A., \& Adebar, P. (2011). Plastic Hinge Lengths in High-Rise Concrete Shear Walls. $A C I$ Structural Journal, 108(2), 148-157.

Cardenas, A. E., \& Magura, D. D. (1972). Strength of High-Rise Shear Walls - Rectangular Cross Section. Special Publication, 36. doi:10.14359/17361

CEB-FIP, C. E.-I. d. B. (1990). CEB-FIP Model Code 1990. London: Thomas Telford.

CERC, C. E. R. C. (2012). Final report: Volume 2: The peromance of Christchurch CBD Buildings. Wellington, NZ.

Dai, H. (2011). An Investigation of Ductile Design of Slender Concrete Structural Walls. (Master of Science), Iowa State University, Ames, Iowa. 
Eligehausen, R. (1983). Local bond stress-slip relationships of deformed bars under generalized excitations : experimental results and analytical model. In E. P. Popov \& V. V. Bertero (Eds.). Berkeley, Calif. :: Earthquake Engineering Research Center, College of Engineering, University of California :.

Fenwick, R., \& Dhakal, R. P. (2007). Material strain limits for seismic design of concrete structures. SESOC: Journal of the NZ Structural Engineering Society, 20(1), pp. 14-28.

fib (2012). Model Code 2010 - Final draft, Volume 2. fib Bulletin No. 66. Lausanne, Switzerland.

Ghorbani-Renani, I., Velev, N., Tremblay, R., Palermo, D., Massicotte, B., \& Léger, P. (2009). Modeling and Testing Influence of Scaling Effects on Inelastic Response of Shear Walls. Structural Journal, 106(3).

Goldsworthy, H. M., \& Gibson, G. (2012). Changes in Seismic Design Philosophy for RC Structures in Areas of Low to Moderate Seismicity Following the Christchurch Earthquake. Paper presented at the 15th World Conference in Earthquake Engineering, Lisbon, Portugal.

Hannewald, P. (2013). Seismic Behavior of Poorly Detailed RC Bridge Piers. EPFL. Retrieved from http://infoscience.epfl.ch/record/188364

Henry, R. S. (2013). Assessment of the Minimum Vertical Reinforcement Limits for RC Walls. Bulletin of the New Zealand Society for Earthquake Engineering, 46(2), 88.

Henry, R. S., Ingham, J., \& Lu, Y. (2014). Experimental testing and modelling to address the performance of RC walls during the 2010/2011 Canterbury earthquakes. Paper presented at the Tenth U.S. National Conference on Earthquake Engineering, Anchorage, Alaska.

Henry, R. S., Lu, Y., Seifi, P., \& Ingham, J. M. (2015, 6-8 Novemeber, 2015). Recent Research to Improve the Seismic Performance of Lightly Reinforced and Precast Concrete Walls. Paper presented at the Proceedings of the Tenth Pacific Conference on Earthquake Engineering, Sydney, Australia.

Hoult, R. D., Goldsworthy, H. M., Lumantarna, E. (2015). Improvements and difficulties associated with the seismic assessment of infrastructure in Australia. Australasian Fire and Emergency Service Authorities Council (AFAC) 2015 Conference, Adelaide, South Australia.

Hyland. (2011). Pyne Gould Corportation Building Site Examination and Materials Tests: Report prepared for: Department of Building and Housing.

International Council of Building Officials (1997). 1997 Uniform Building Code, Vol. 2. Whittier, CA.

Kazaz, 1. (2013). Analytical Study on Plastic Hinge Length of Structural Walls. Journal of Structural Engineering(11), 1938.

Kupfer, H. B., \& Gerstle, K. H. (1973). Behavior of Concrete under Biaxial Stresses. Journal of the Engineering Mechanics Division, 99(4), 13.

Kupfer, H., Hilsdorf, H. K., \& Rusch, H. (1969). Behavior of Concrete Under Biaxial Stresses. Journal Proceedings, 66(8). doi: 10.14359/7388

Lu, Y., Henry, R. S., \& Ma, Q. (2014). Modelling and Experimental Plan of Reinforced Concrete Walls with Minimum Vertical Reinforcement. Paper presented at the Tenth U.S. National Conference on Earthquake Engineering, Anchorage, Alaska.

Lu, Y., Henry, R. S., Gultom, R., \& Ma, Q. (2015). Experimental testing and modelling of reinforced concrete walls with minimum vertical reinforcement. Paper presented at the $2015 \mathrm{New}$ Zealand Society for Earthquake Engineering Annual Technical Conference, Rotorua, New Zealand.

Luu, H., Léger, P., \& Tremblay, R. (2013). Seismic demand of moderately ductile reinforced concrete shear walls subjected to high-frequency ground motions. Canadian Journal of Civil Engineering, 4l(2), 125-135.

Menegon, S.J., H.H. Tsang, and J.L. Wilson. Overstrength and ductility of limited ductile RC walls: from the design engineers perspective. in Proceedings of the Tenth Pacific Conference on Earthquake Engineering. 2015. Sydney, Australia.

Moehle, J. P. (1992). Displacement-Based Design of RC Structures Subjected to Earthquakes. Earthquake Spectra, 8(3), 403-428. doi:doi:10.1193/1.1585688

Moehle, J. (2015). Seismic design of reinforced concrete buildings. New York, N.Y.: McGraw-Hill Education LLC. 
Mohr, D. S. (2007). Nonlinear Analysis and Performance Based Design Methods for Reinforced Concrete Coupled Shear Walls. (Master of Science in Civil Engineering), University of Washington, Seattle, U.S.A.

Morris, G. J., Bull, D. K., \& Bradley, B. A. (2015). In Situ Conditions Affecting the Ductility Capacity of Lightly Reinforced Concrete Wall Structures in the Canterbury Earthquake Sequence. Bulletin of the NZ Society of Earthquake Engineering, 48(3), 191-204.

Mortezaei, A., \& Ronagh, H. R. (2012). Plastic hinge length of FRP strengthened reinforced concrete columns subjected to both far-fault and near-fault ground motions. Scientia Iranica, 19(6), 1365-1378.

Oesterle, R. G., Fiorato, A. E., Johal, L. S., Carpenter, J. E., Russell, H. G., \& Corley, W. G. (1976). Earthquake Resistant Structural Walls - Tests of Isolated Walls (pp. 318). Skokie, Illinois: Report to the National Science Foundation, Construction Technology Laboratories, Portland Cement Association.

Palermo, D., \& Vecchio, F. (2002). Behaviour and Analysis of Reinforced Concrete Walls Subjected to Reversed Cyclic Loading. Publication No. 2002-01, Department of Civil Engineering, University of Toronto, $351 \mathrm{pp}$.

Palermo, D., \& Vecchio, F. J. (2007). Simulation of Cyclically Loaded Concrete Structures Based on the Finite-Element Method. Journal of Structural Engineering, 133(5), 728-738. doi: 10.1061/(ASCE)0733-9445(2007)133:5(728)

Patel, V. J., Van, B. C., Henry, R. S., \& Clifton, G. C. (2015). Effect of reinforcing steel bond on the cracking behaviour of lightly reinforced concrete members. Construction and Building Materials, 96, 238-247. doi: http://dx.doi.org/10.1016/j.conbuildmat.2015.08.014

Paulay, T. (1986). The Design of reinforced concrete ductile shear walls for earthquake resistance: University of Canterbury, Department of Civil Engineering.

Paulay, T., \& Priestley, M. J. N. (1992). Seismic design of reinforced concrete and masonry buildings: New York : Wiley, c1992.

Priestley, M. J. N., Calvi, G. M., \& Kowalsky, M. J. (2007). Displacement-based seismic design of structures / M. J. N. Priestley, Gian Michele Calvi, Mervyn J. Kowalsky: Pavia : IUSS Press : Fondazione Eucentre, 2007.

Priestley, M. J. N., \& Park, R. (1984). Strength and Ductility of Bridge Substructures. RRU Bulletin 71, National Roads Board, Wellington, New Zealand.

Priestley, M. J. N., \& Park, R. (1987). Strength and Ductility of Concrete Bridge Columns Under Seismic Loading. Structural Journal, 84(1). doi:10.14359/2800

Richart, F. E., Brandtzaeg, A., \& Brown, R. L. (1928). A study of the failure of concrete under combined compressive stresses. University of Illinois Bulletin; v. 26, no. 12.

Sagbas, G. (2007). Nonlinear Finite Element Analysis of Beam-Column Subassemblies. (Master of Applied Science), University of Toronto, Toronto, Canada.

Seckin, M. (1981). Hysteretic Behaviour of Cast-in-Place Exterior Beam-Column-Slab Subassemblies. (Ph.D. Thesis), University of Toronto, Toronto, Canada.

Smith, P., \& England, V. (2012). Independent Assessment on Earthquake Performance of Gallery Apartments - 62 Gloucester Street: Report prepared for the Canterbury Earthquakes Royal Commision, available at http://canterbury.royalcommission.govt.nz/documents-by$\mathrm{key} / 20120217.3188$.

SRIA. (2015). Guide to Seismic Design and Detailing of Reinforced Concrete Buildings in Australia (P. McBean, J. W. Woodside, S. Munter, \& E. Lume Eds. First ed.): Steel Reinforcement Institute of Australia.

Sritharan, S., Beyer, K., Henry, R. S., Chai, Y. H., Kowalsky, M., \& Bull, D. (2014). Understanding Poor Seismic Performance of Concrete Walls and Design Implications. Earthquake Spectra, 30(1), 307-334.

Standards Association NZ. (2006a). NZS 3101: Part1:2006, Concrete Structures Standard - The Design of Concrete Structures.

Standards Association NZ. (2006). NZS 3101: Part2:2006, "Concrete Structures Standard Part 2 Commentary on the Design of Concrete Structures".

Standards Australia. (2009). AS 3600-2009: Concrete Structures. 
Standards Australia. (2014). AS 3600-2009 Supp 1:2014 : Concrete structures - Commentary (Supplement to AS 3600-2009).

Standards Australia/New Zealand. (2001). AS/NZS 4671:2001 : Steel Reinforcing Materials.

Thomsen, J., \& Wallace, J. (2004). Displacement-Based Design of Slender Reinforced Concrete Structural Walls_Experimental Verification. Journal of Structural Engineering, 130(4), 618630. doi: doi:10.1061/(ASCE)0733-9445(2004)130:4(618)

Vecchio, F. (1992). Finite Element Modeling of Concrete Expansion and Confinement. Journal of Structural Engineering, 118(9), 2390-2406.

Vecchio, F., Lai, D., Shim, W., \& Ng, J. (2000). Disturbed Stress Field Model for Reinforced Concrete: Validation. Journal of Structural Engineering, 126(9), 1070.

Wallace, J. W., \& Moehle, J. P. (1992). Ductility and Detailing Requirements of Bearing Wall Buildings. Journal of Structural Engineering, 118(6), 1625-1644.

Walraven, J. C. (1981). Fundamental Analysis of Aggregate Interlock. Journal of the Structural Division, 107(11), 25.

Wibowo, A., Wilson, J., Lam, N. T. K., \& Gad, E. F. (2013). Seismic performance of lightly reinforced structural walls for design purposes. Magazine of Concrete Research, 65, 809-828.

Wibowo, A., Wilson, J., Lam, N., Gad, E. F., Lu, Y., \& Henry, R. S. (2014). Discussion: Seismic performance of lightly reinforced structural walls for design purposes. Magazine of Concrete Research, 66, 1073-1074.

Wong, P., \& Vecchio, F. (2002). Vector2 and FormWorks User Manual. Department of Civil Engineering, University of Toronto.

Wood, S. L. (1989). Minimum Tensile Reinforcement Requirements In Walls. ACI Structural Journal, 86(5), 582-591. 


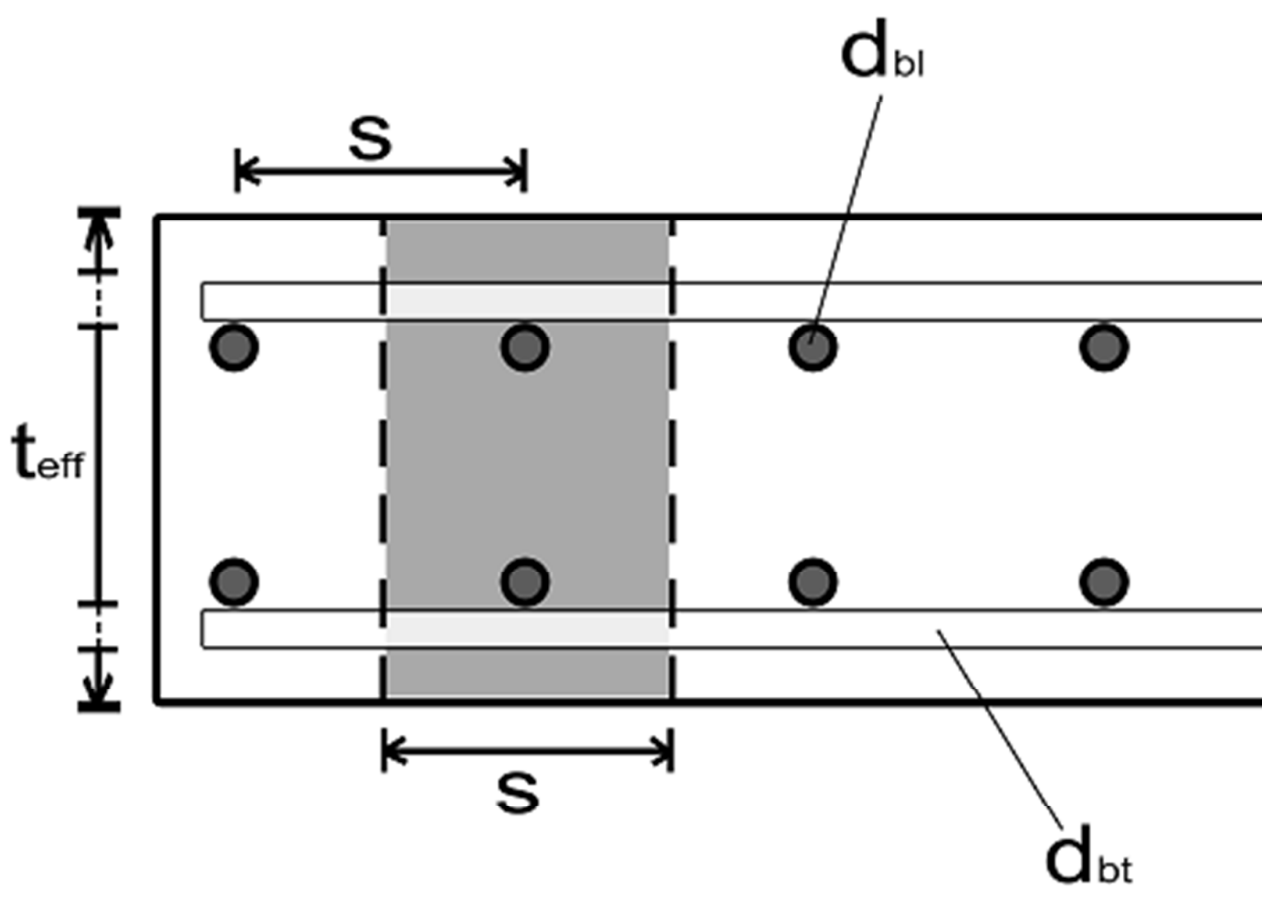

Figure 1 Cross section of a typical RC wall with shaded area $A_{\text {eff }}$ 

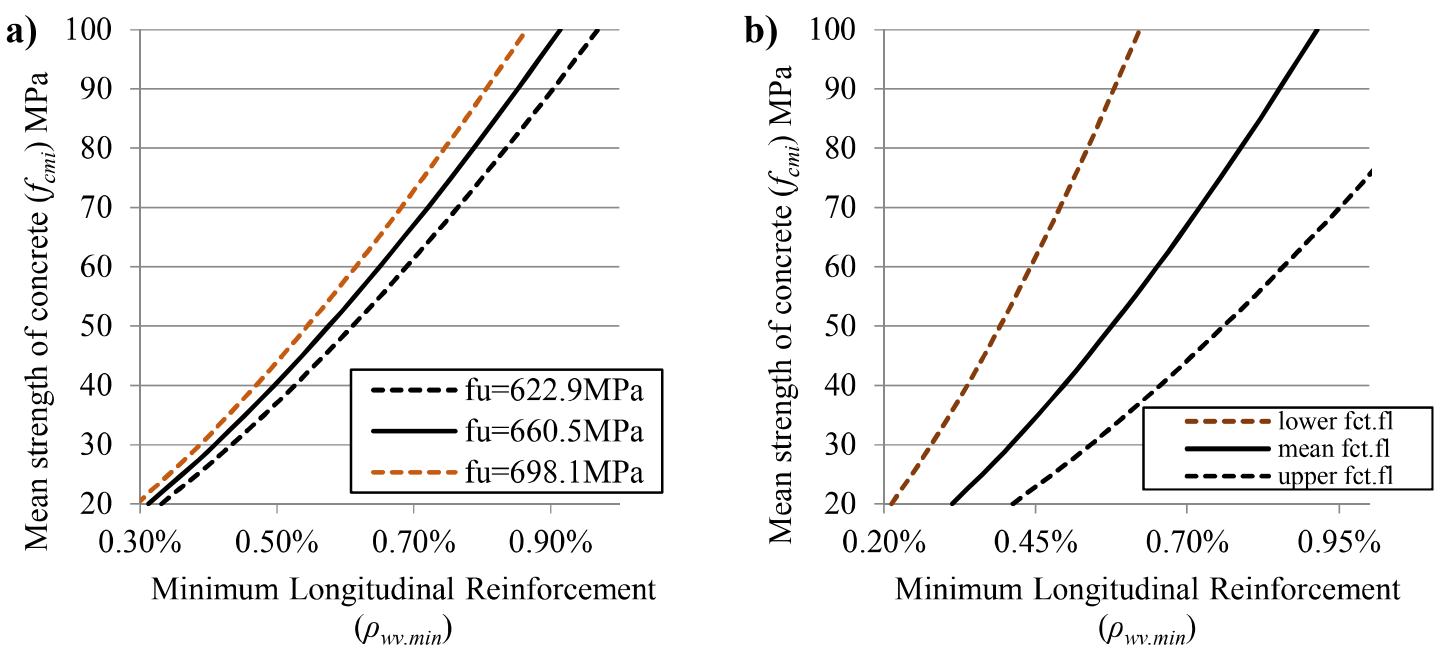

Figure 2 Minimum longitudinal reinforcement ratio required for a range of concrete strengths with lower, mean and upper bound (a) ultimate strength of steel and (b) flexural tensile strength of concrete 
a)

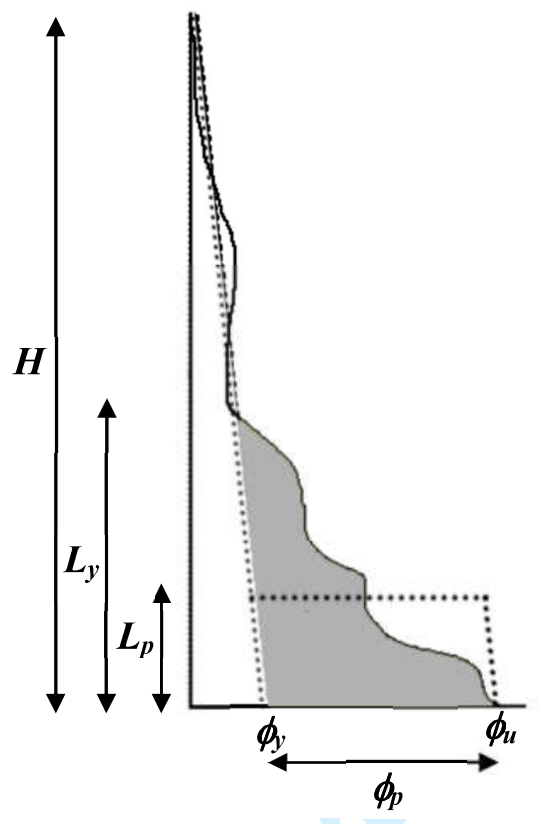

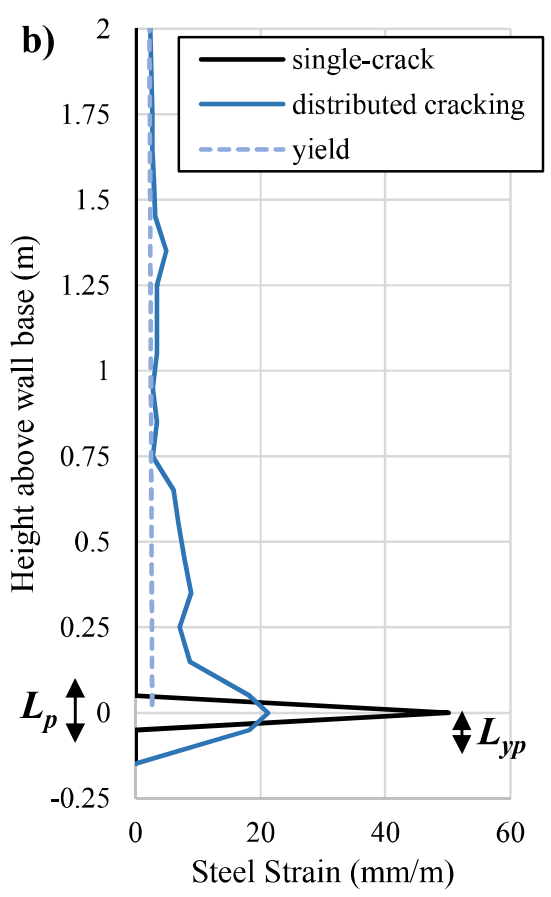

Figure 3 (a) Curvature distribution (solid line) along RC cantilever wall with idealised profile (dotted line) and (b) expected strain distribution results 

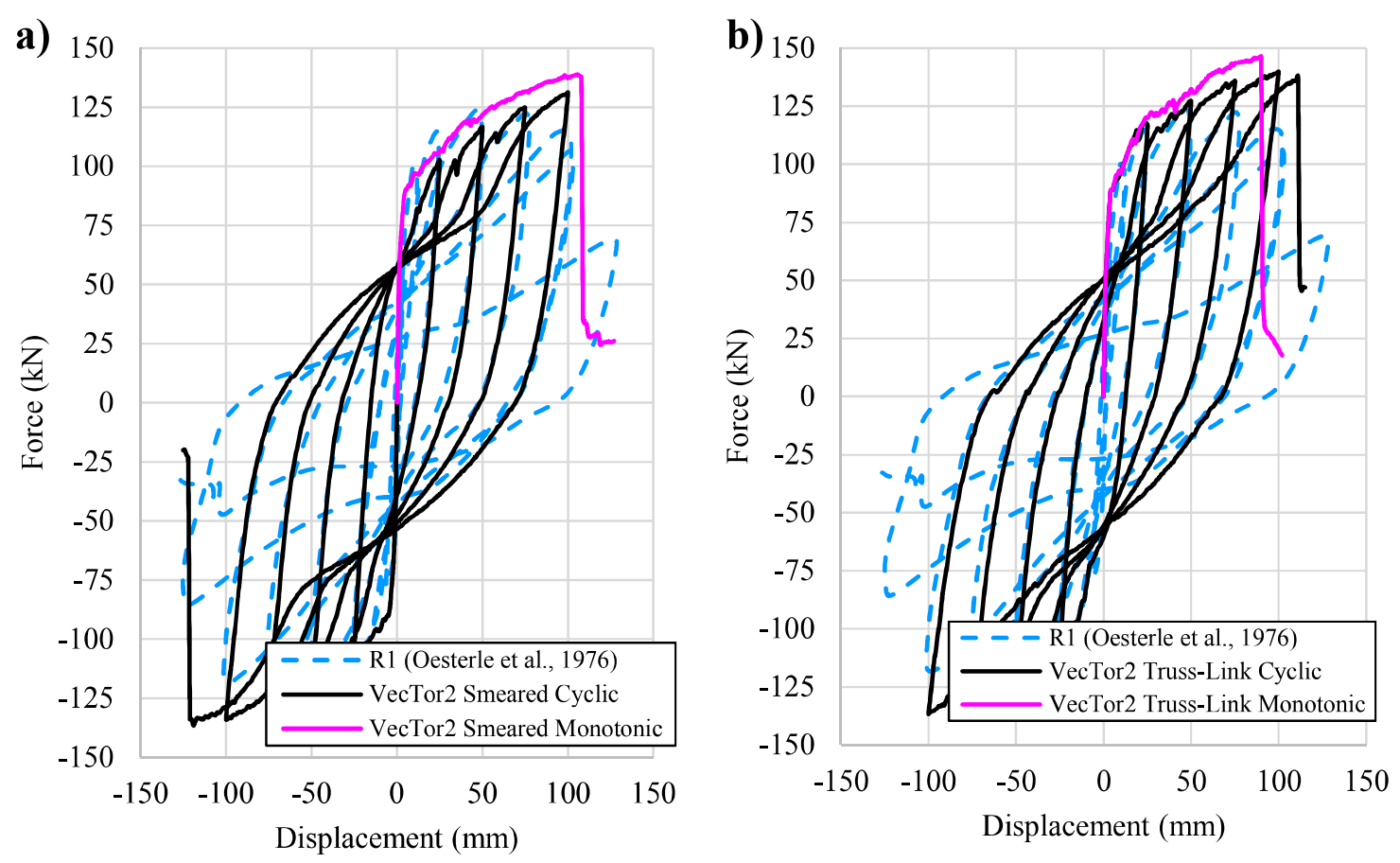

Figure 5 Force-displacement results from VecTor2 using (a) smeared vertical reinforcement and (b) discrete truss-link elements 


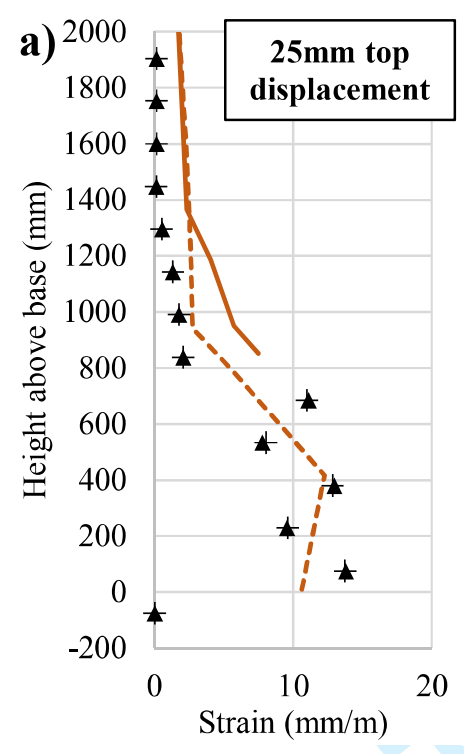

b)

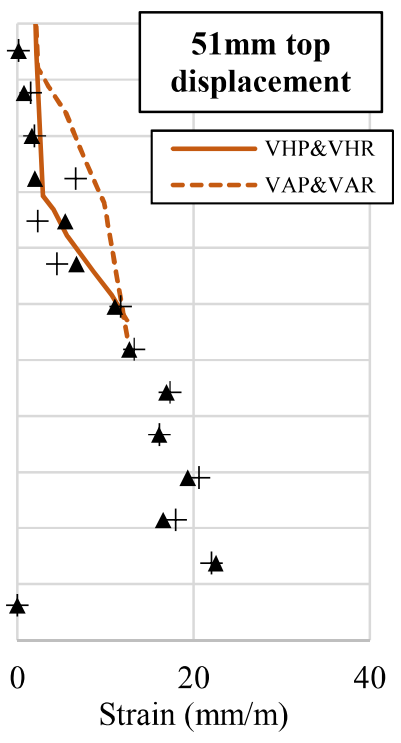

c)

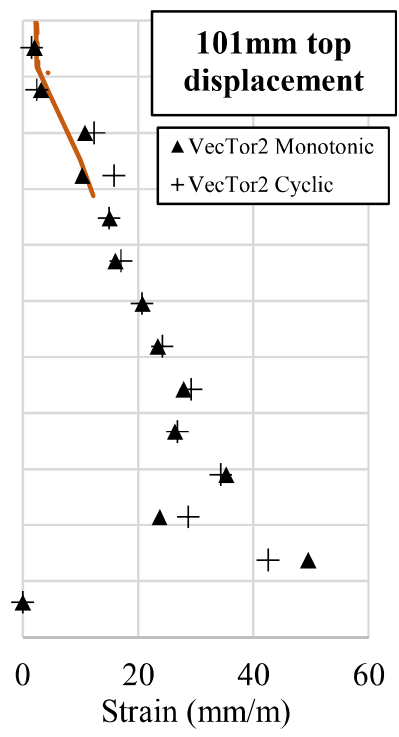

Figure 6 VecTor2 steel strain distribution results from the smeared model (where VHP \& VHR correspond to the strain gauges on the west toe of the wall and VAP \& VAR are the gauges on the east toe) 


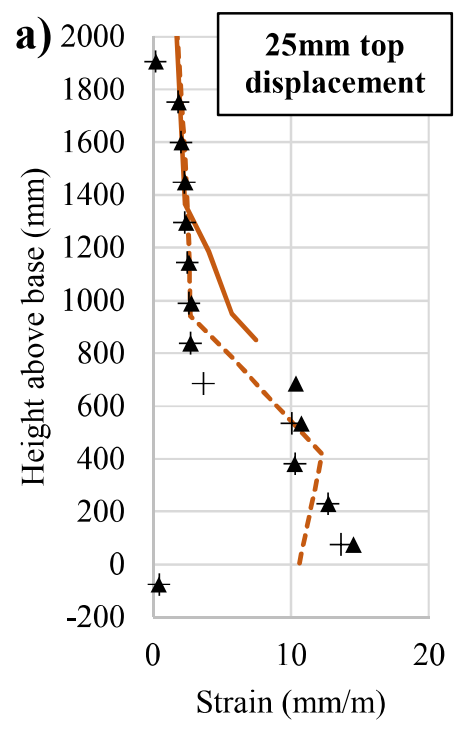

b)

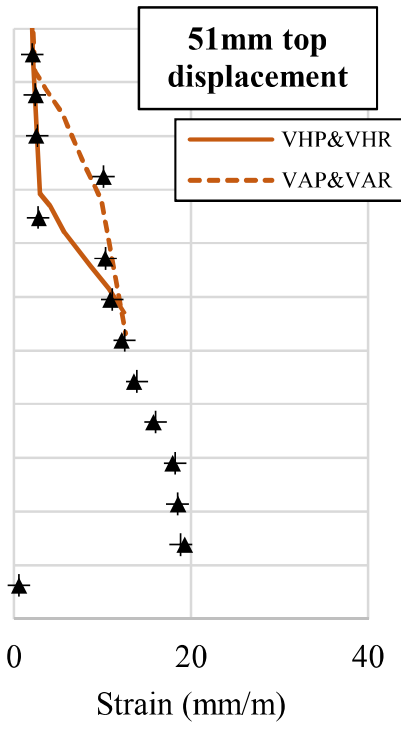

c)

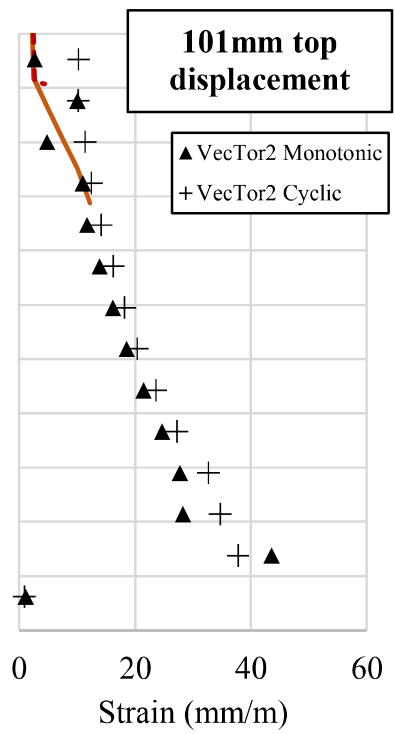

Figure 7 VecTor2 steel strain distribution results from the truss-link model (where VHP \& VHR correspond to the strain gauges on the west toe of the wall and VAP \& VAR are the gauges on the east 

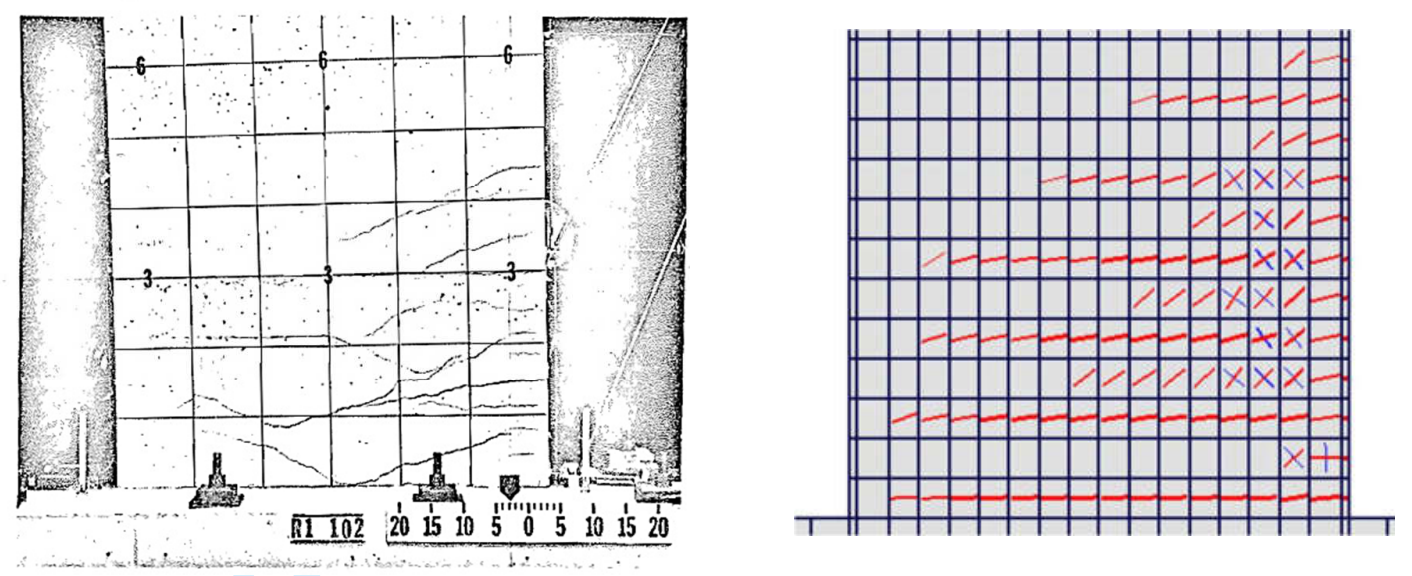

Figure 9 Cracking pattern at 76mm deflection for (a) specimen R1 (Oesterle et al., 1976) and (b) VecTor2 
Figure 11 (a) Mesh setup and cracking distribution from VecTor2 monotonic and (b) experimental observations from Lu et al. (2015) 

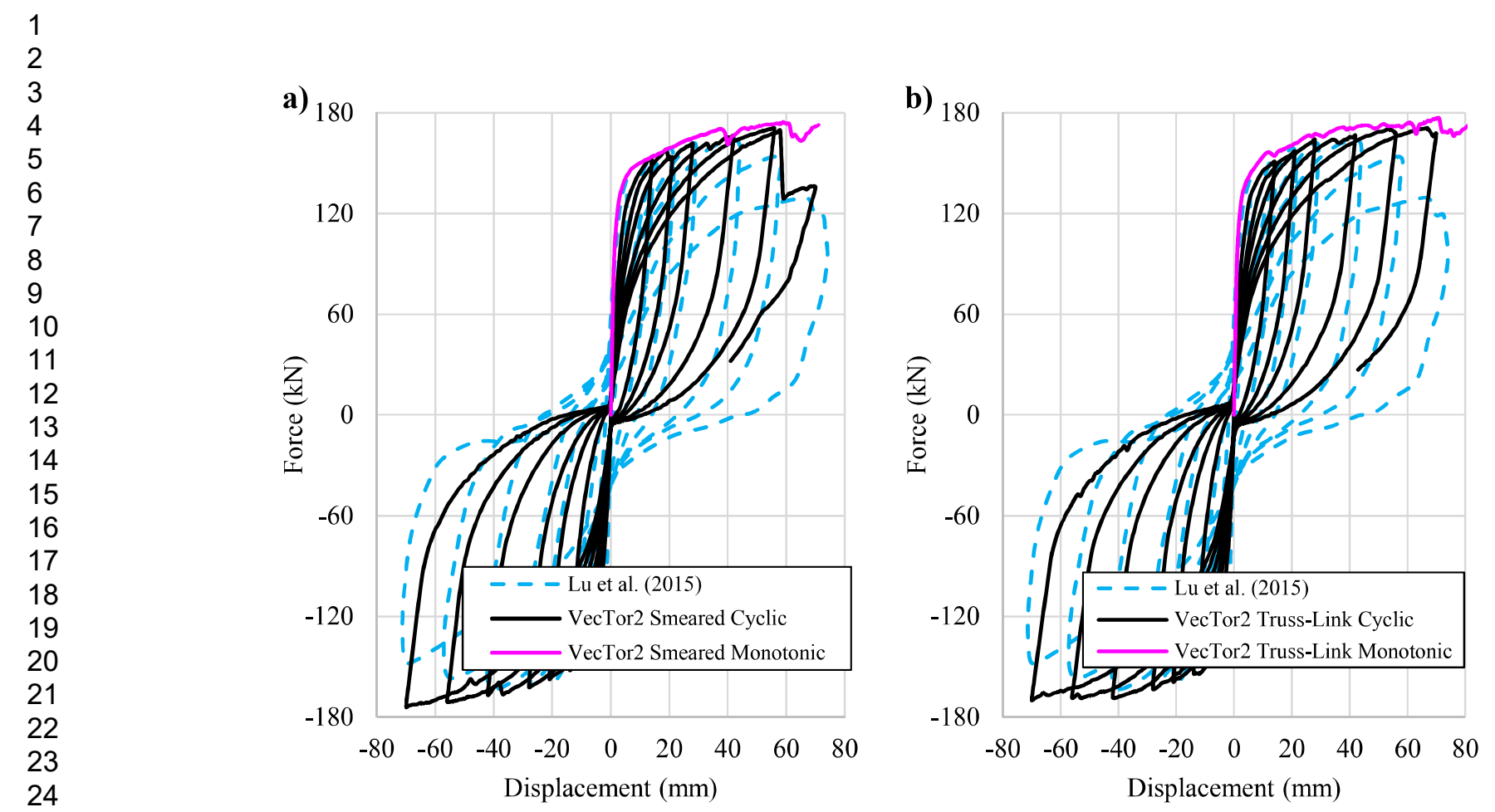

Figure 12 Force-displacement results from VecTor2 for wall C1 with (a) smeared and (b) truss-link models 

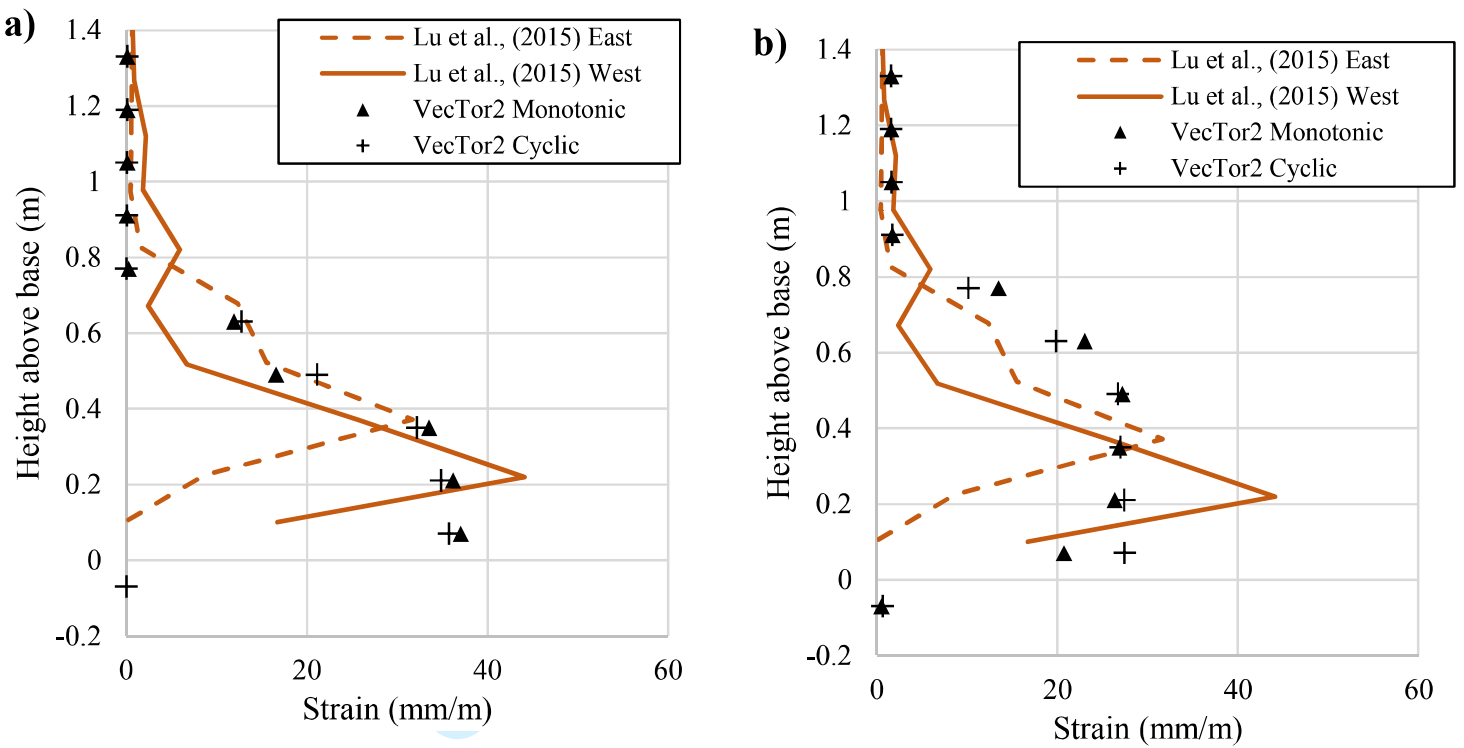

Figure 13 Steel strain distribution comparison for (a) Model 1 (smeared) and (b) Model 2 (truss-link) at a wall drift of $1.5 \%(42 \mathrm{~mm}$ top displacement) 


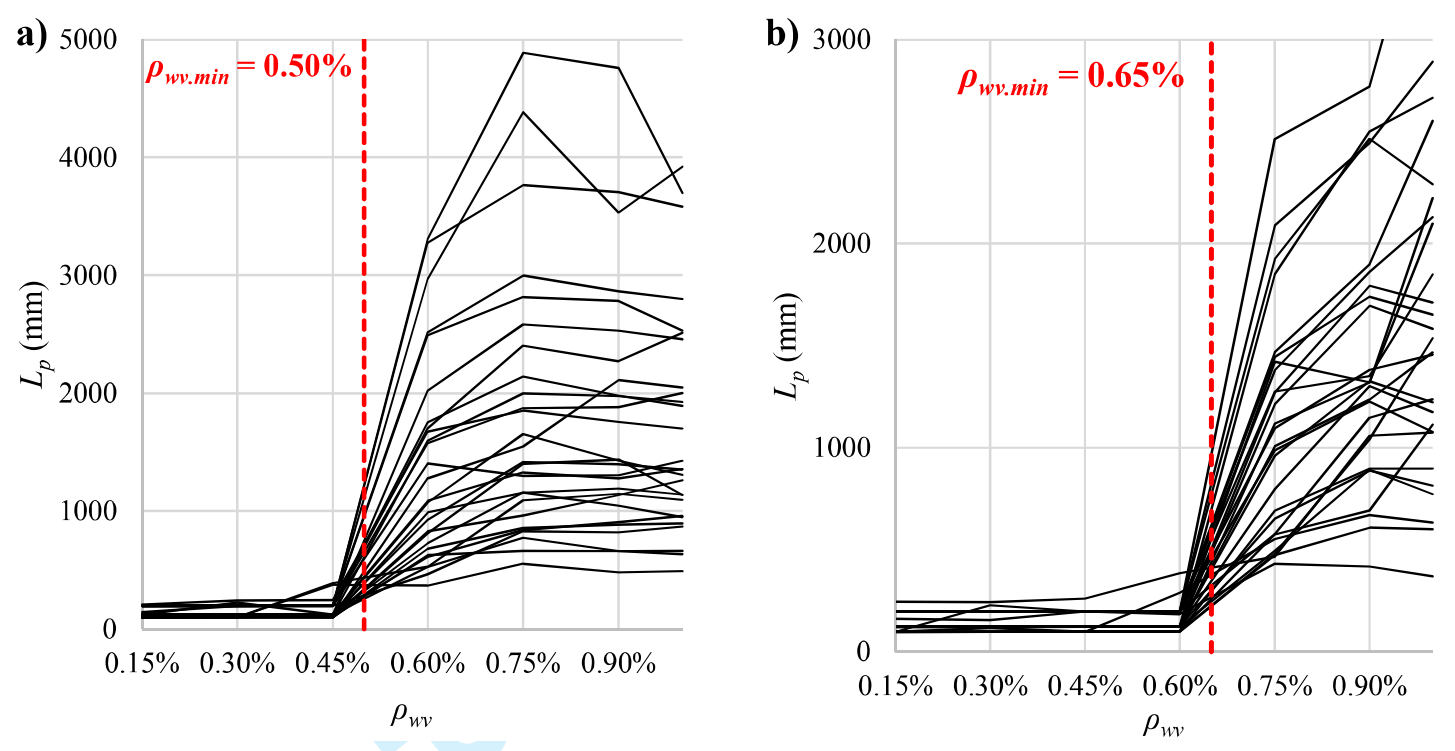

Figure 14 Plastic hinge length results as a function of longitudinal reinforcement ratio for all of the walls with a $f_{c m i}$ of (a) $40 \mathrm{MPa}$ and (b) $60 \mathrm{MPa}$ 
a)

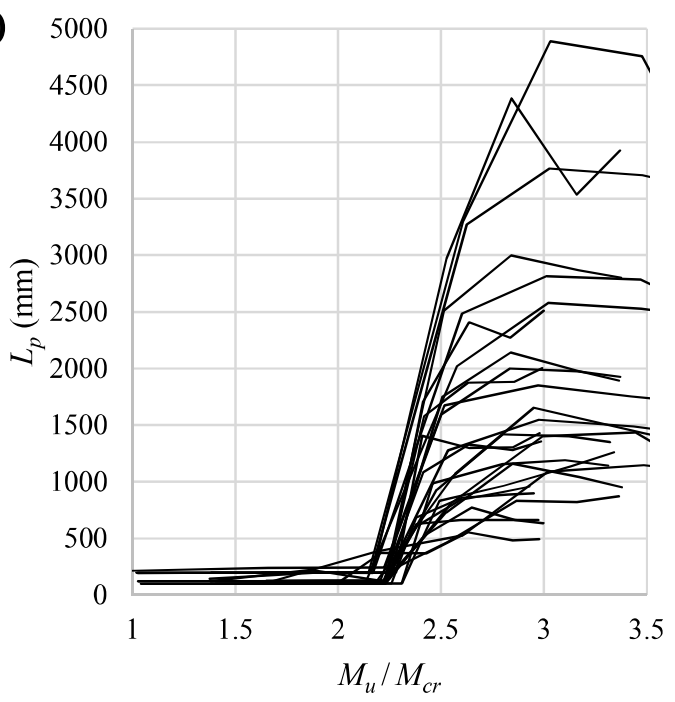

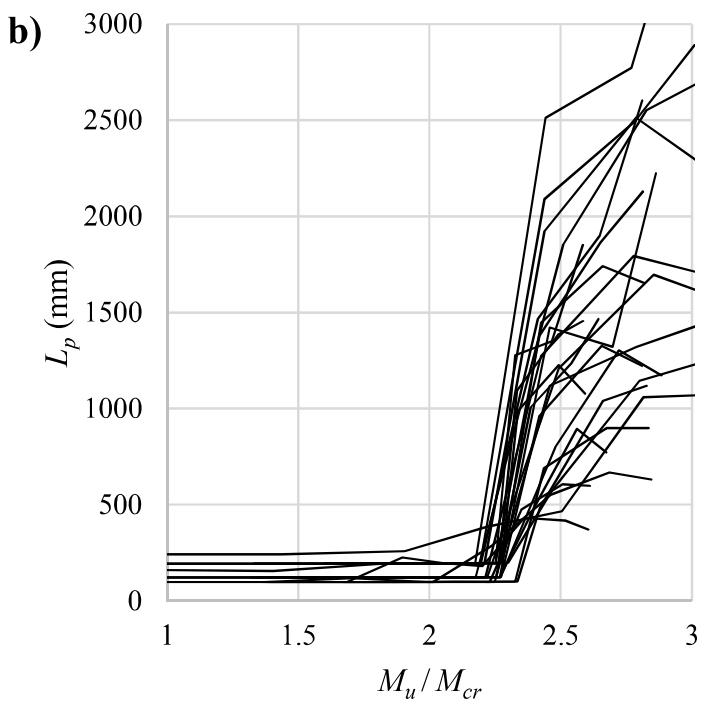

Figure 15 Plastic hinge length results as a function of the ultimate to cracking moment ratio for all of the walls with a $f_{c m i}$ of (a) $40 \mathrm{MPa}$ and (b) $60 \mathrm{MPa}$ 

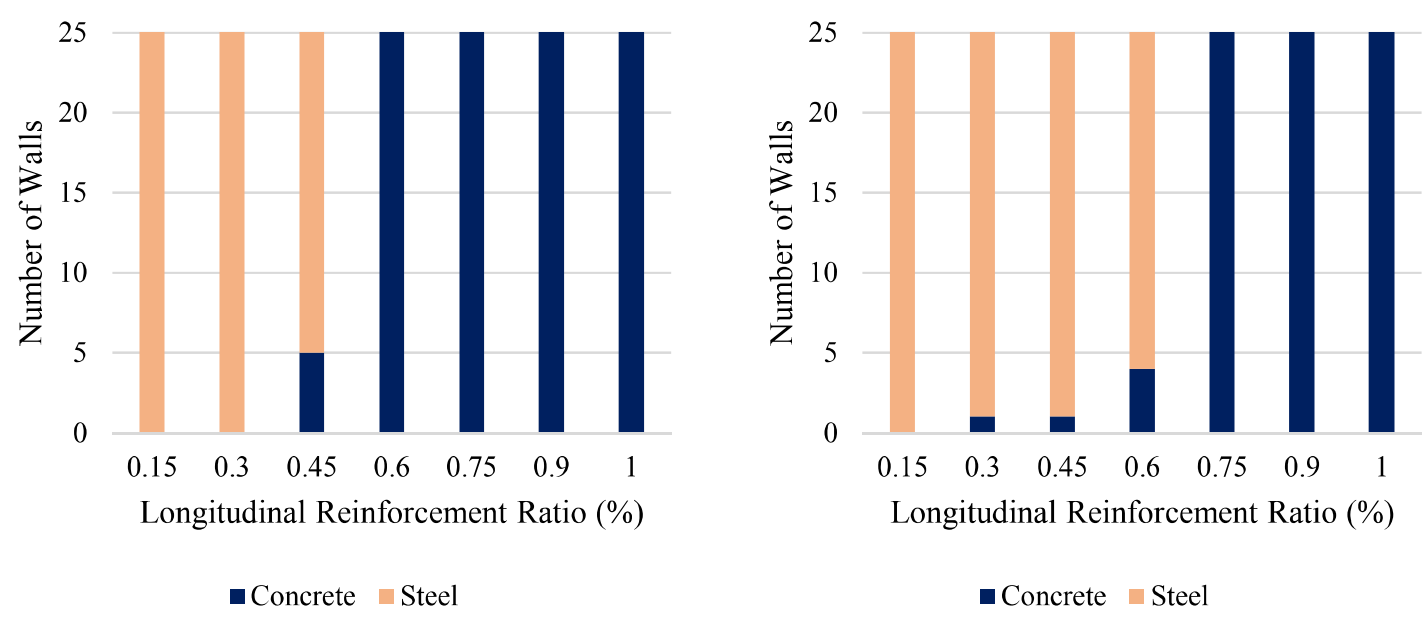

Figure 16 Governing strains in the walls as a function of the longitudinal reinforcement content for walls with a $f_{c m i}$ of (a) $40 \mathrm{MPa}$ and (b) $60 \mathrm{MPa}$ 

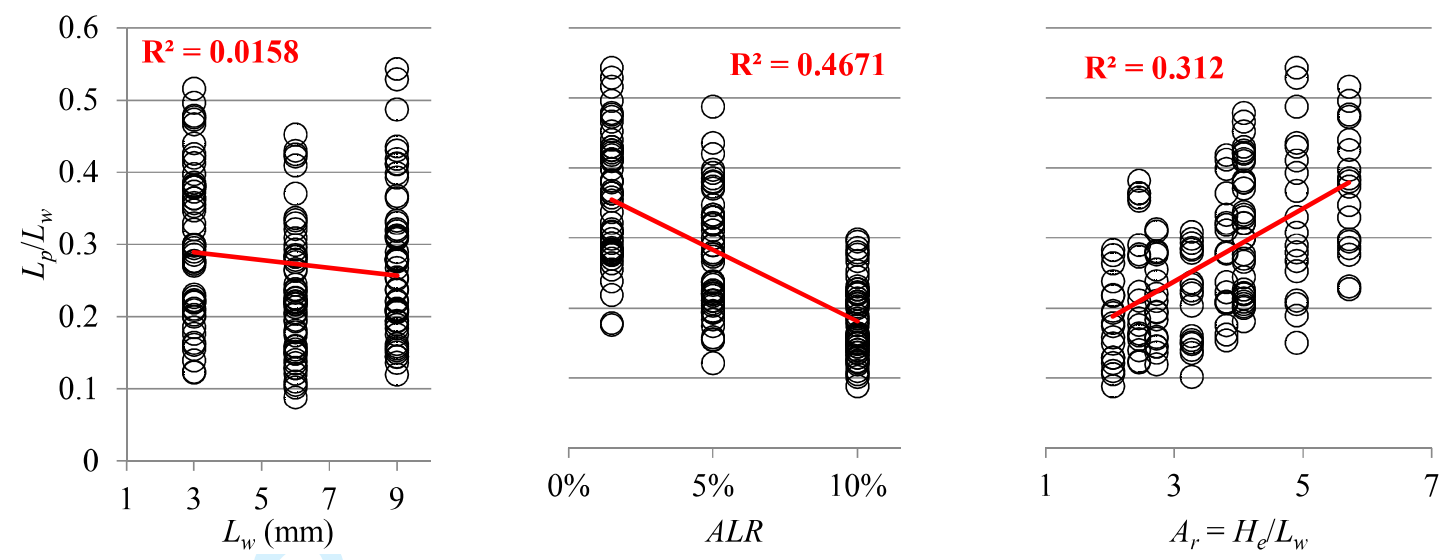

Figure 17 Results of plastic hinge length normalised to the respective wall length with wall parameters (a) wall length (b) axial load ratio and (c) aspect ratio 
1

2

3

4

5

6

7

8

9

10

11

12

13

14

15

16

17

18

19

20

21

22

23

24

25

26

27

28

29

30

31

32

33

34

35

36

37

38

39

40

41

42

43

44

45

46

47

48

49

50

51

52

53

54

55

56

57

58

59

60
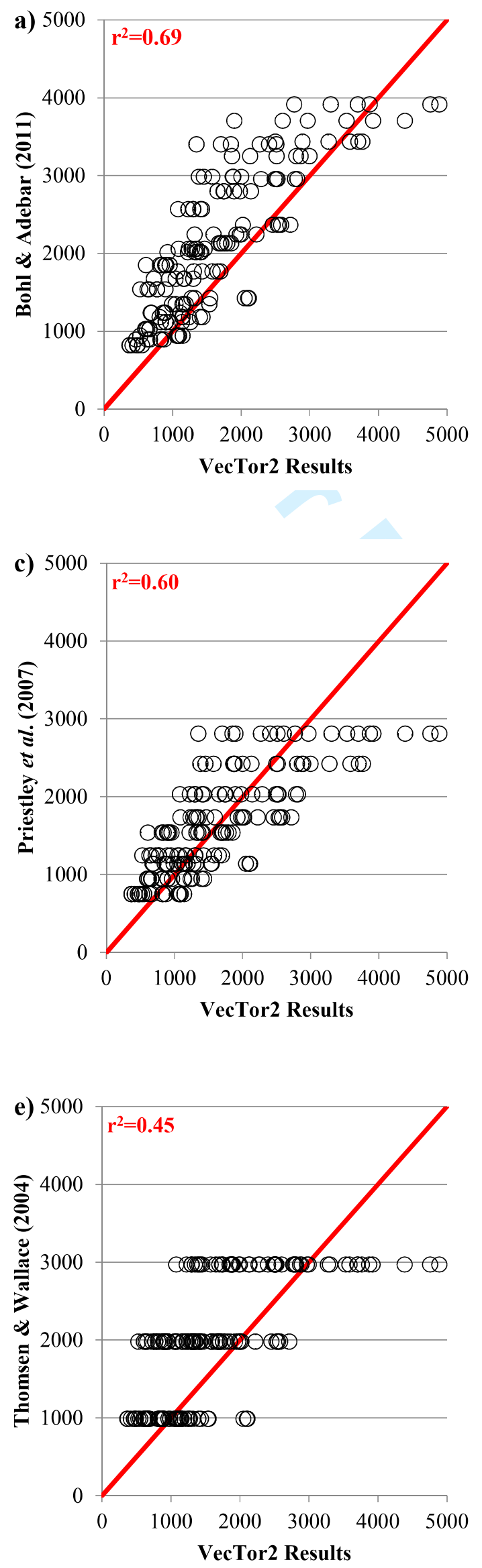
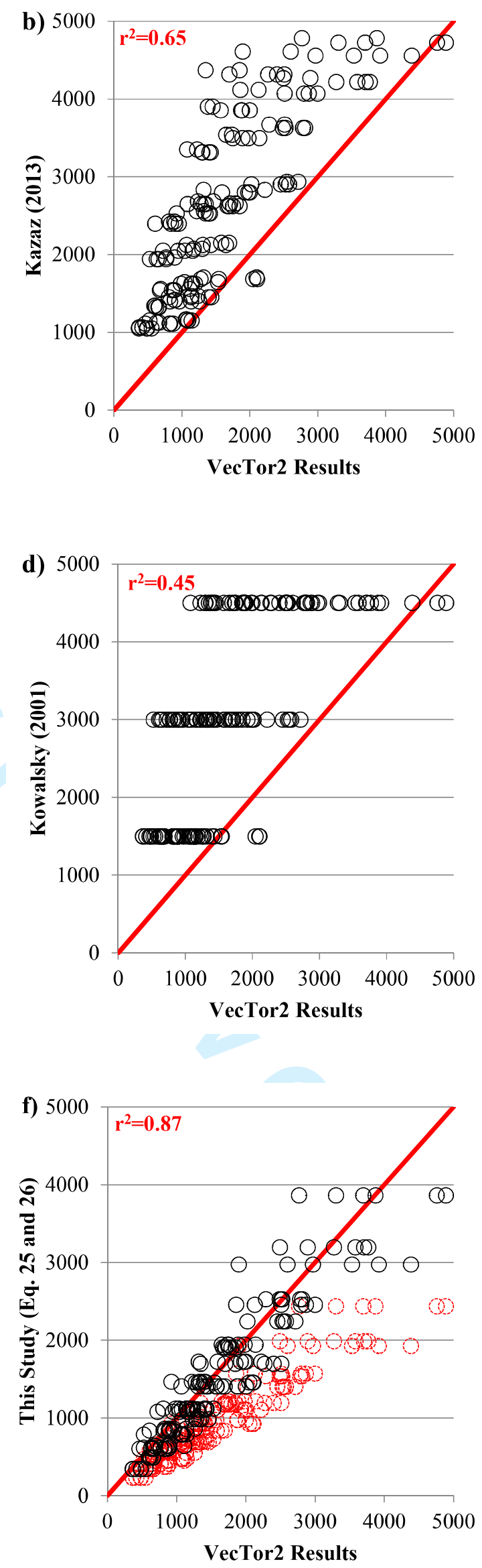

Figure 18 Comparison of VecTor2 plastic hinge length results to the proposed estimations from various studies URL: http:/mc.manuscriptcentral.com/ueqe Email: gencturk@usc.edu 
Figure 19 Cross-sections of wall specimens (a) W1 and (b) W2 from Altheeb (2016) 


\section{Page 51 of 85}

Journal of Earthquake Engineering

1
2
3
4
5
6
7
8
9
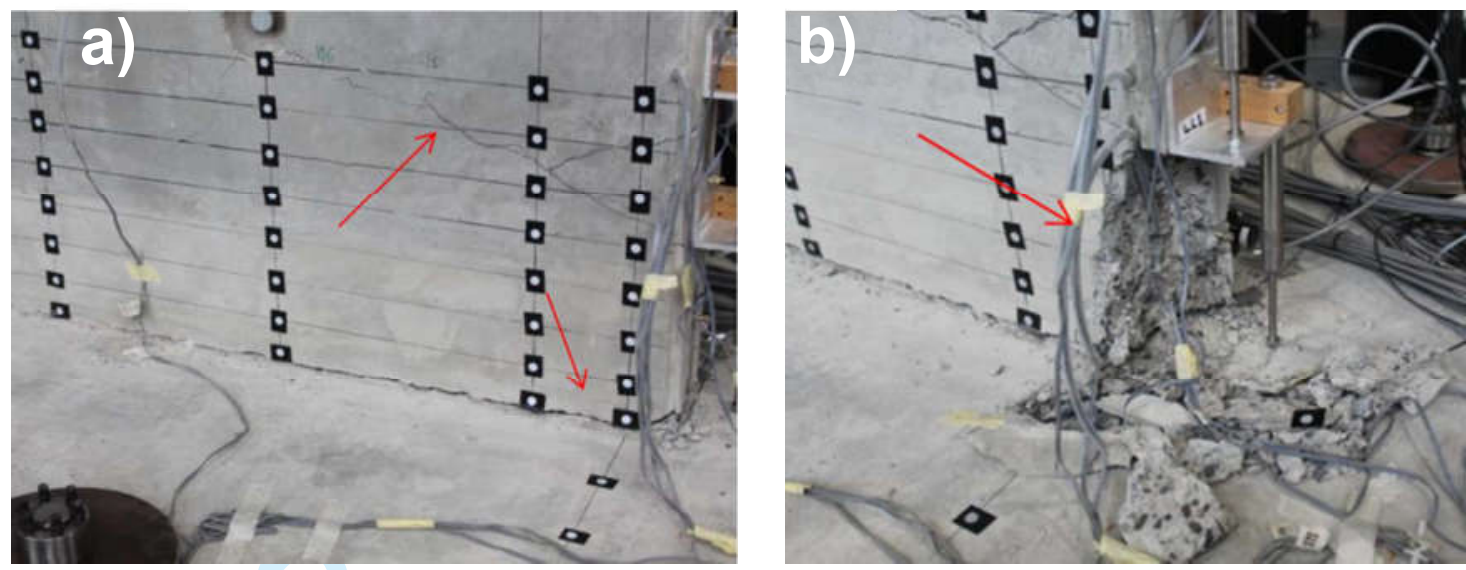

Figure 20 Damage state of wall specimen W1 (Altheeb, 2016) at top wall displacement of (a) $50 \mathrm{~mm}$ and (b) $70 \mathrm{~mm}$ 


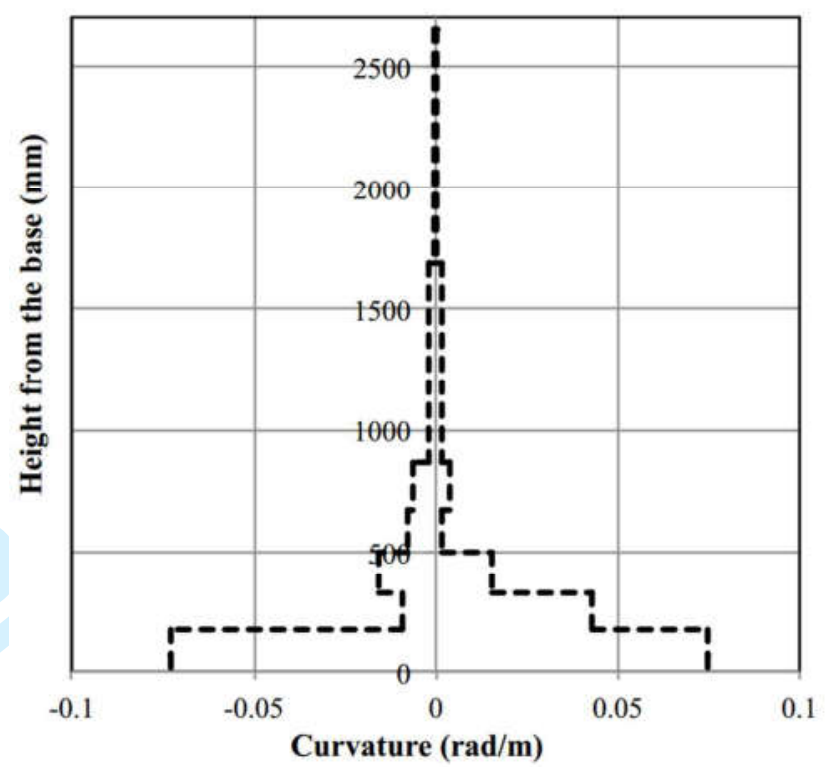

Figure 21 Curvature distribution for W2 (Albidah, 2016) at $80 \mathrm{~mm}$ top wall displacement 
Table 1 Strain hardening ratio values for common steel reinforcing bars in Australia

\begin{tabular}{ccc}
\cline { 2 - 3 } Type & \multicolumn{2}{c}{$f_{u} / f_{y}$} \\
\hline D500L & 1.030 & Menegon et al. $(2015)$ \\
D500N & 1.080 & 1.056 \\
D500E & 1.150 & 1.201 \\
\hline
\end{tabular}

Table 2 Details of the $\mathrm{RC}$ wall specimen $\mathrm{R} 1$

\begin{tabular}{lcccccccc}
\hline & \multicolumn{3}{c}{$H_{e}$} & $A L R$ & & \\
$f_{c}^{\prime}(\mathrm{MPa})$ & $f_{c t . f l}(\mathrm{MPa})$ & $L_{w}(\mathrm{~mm})$ & $t_{w}(\mathrm{~mm})$ & $(\mathrm{mm})$ & $(\%)$ & $\rho_{w v}{ }^{1}(\%)$ & $\rho_{w h}(\%)$ & $\rho_{w b}{ }^{2}(\%)$ \\
44.7 & 4.5 & 1905 & 101 & 4572 & 0.4 & 0.25 & 0.31 & 1.74 \\
\hline${ }^{1}$ reinforcement ratio in the web \\
${ }^{2}$ longitudinal reinforcement ratio in the boundary ends
\end{tabular}

Table 3 Steel reinforcing properties for specimen R1

\begin{tabular}{ccccc}
\hline$d_{b l}(\mathrm{~mm})$ & $E_{s}(\mathrm{MPa})$ & $f_{y}(\mathrm{MPa})$ & $f_{u}(\mathrm{MPa})$ & $0.6 \varepsilon_{s u}(\mathrm{~mm} / \mathrm{m})$ \\
\hline 6 & 216,495 & 522 & 700 & 73.0 \\
9.525 & 191,674 & 511 & 765 & 58.8 \\
\hline
\end{tabular}

Table 4 Walls used in VecTor2 with varying parameters

\begin{tabular}{cccccccc}
\hline$L_{w}(\mathrm{~m})$ & $t(\mathrm{~m})$ & $a$ & $H_{e}(\mathrm{~m})$ & $A L R(\%)$ & $f_{c m i}(\mathrm{MPa})$ & $\rho_{w v}(\%)$ & $\rho_{w h}(\%)$ \\
\hline 3 & 0.2 & $2.5,4.1,5.7$ & $7.35,12.25,17.15$ & $1.5,5,10$ & 40,60 & $0.15-1.0$ & 0.25 \\
6 & 0.2 & $2.0,3.3,4.1$ & $12.25,19.60,24.50$ & $1.5,5,10$ & 40,60 & $0.15-1.0$ & 0.25 \\
9 & 0.25 & $2.7,3.8,4.9$ & $24.50,34.30,44.10$ & $1.5,5,10$ & 40,60 & $0.15-1.0$ & 0.25 \\
\hline
\end{tabular}

Table 5 Mean and standard deviations of plastic hinge length from the VecTor2 results

\begin{tabular}{ccc}
\hline$L_{w}(\mathrm{~m})$ & $\mu(\mathrm{mm})$ & $\sigma(\mathrm{mm})$ \\
\hline 3 & 135.8 & 73.3 \\
6 & 128.8 & 26.5 \\
9 & 195.4 & 0.7 \\
\hline
\end{tabular}

Table 6 Details of the RC wall specimen W1

\begin{tabular}{ccccccccc} 
& $f_{c}^{\prime}(\mathrm{MPa})$ & $f_{c t . f l}(\mathrm{MPa})$ & $L_{w}(\mathrm{~mm})$ & $t_{w}(\mathrm{~mm})$ & $H_{e}(\mathrm{~mm})$ & $A L R(\%)$ & $\rho_{w v}(\%)$ & $\rho_{w h}(\%)$ \\
\cline { 2 - 8 } $\mathrm{W} 1$ & 35.2 & 3.7 & 900 & 120 & 2750 & 5 & 0.33 & 0.30 \\
$\mathrm{~W} 2$ & 34.7 & 3.6 & 900 & 120 & 2750 & 5 & 0.66 & 0.30 \\
\hline
\end{tabular}


Table 7 Steel reinforcing properties for specimens W1 and W2

\begin{tabular}{crcc}
\hline$d_{b l}(\mathrm{~mm})$ & $E_{s}(\mathrm{MPa})$ & $f_{y}(\mathrm{MPa})$ & $f_{u}(\mathrm{MPa})$ \\
\hline 10 & 200,000 & 500 & 720 \\
\hline
\end{tabular}

Table 8 Plastic hinge length estimates for wall specimen W2

\begin{tabular}{cccccccc}
\hline & $\begin{array}{c}\text { Experimental } \\
\text { (W2) }\end{array}$ & $\begin{array}{c}\text { This } \\
\text { Study } \\
\text { (Eqn. 25) }\end{array}$ & $\begin{array}{c}\text { Bohl \& } \\
\text { Adebar } \\
(2011)\end{array}$ & $\begin{array}{c}\text { Kazaz } \\
(2013)\end{array}$ & $\begin{array}{c}\text { Priestley } \\
\text { et al. } \\
(2007)\end{array}$ & $\begin{array}{c}\text { ICBO } \\
(1997)\end{array}$ & $\begin{array}{c}\text { Thomsen } \\
\& \\
\text { Wallace } \\
(2004)\end{array}$ \\
\hline$L_{p}(\mathrm{~mm})$ & 235.5 & 207.4 & 293.7 & 365 & 453 & 450 & 297 \\
\hline
\end{tabular}

